INRA Prod. Anim., 2006, 19 (4), 245-264

\section{Implication des mitochondries dans la biologie musculaire : un rôle clé au cours du développement, de la croissance et de la fonte musculaire}

P. HERPIN ${ }^{1}$, M. DAMON ${ }^{2}$, J.-F. HOCQUETTE ${ }^{3}$, F. MÉDALE , L. MOSONI ${ }^{5}$, G. STÉPIEN ${ }^{5}$, C. WRUTNIAK-CABELLO', G. CABELLO'

${ }^{1}$ INRA, Direction Scientifique Adjointe Animal et Produits Animaux, F-35590 Saint-Gilles, France 2 INRA, Agrocampus, UMR1079 Systèmes d'élevage, Nutrition animale et humaine, F-35590 Saint-Gilles, France 3 INRA, UR1213 Herbivores, F-63122 Saint-Genès Champanelle, France ${ }^{4}$ INRA, IFREMER, Université Bordeaux, UMR1067 Nutrition Aquaculture et Génomique, F-64310 Saint-Pée-sur-Nivelle, France ${ }^{5}$ INRA, Université Clermont I, UMR1019 Nutrition Humaine, F-63122 Saint-Genès Champanelle, France ${ }^{6}$ INRA, ENSAM, Université Montpellier 2,UMR 866 Différenciation Cellulaire et Croissance, 2 place Pierre Viala, F-34060 Montpellier, France

Courriel : Patrick.Herpin@rennes.inra.fr

Les mitochondries sont potentiellement impliquées dans la régulation de processus physiologiques multiples qui conditionnent le développement, la croissance et les propriétés du muscle des animaux d'élevage et le déterminisme de la fonte musculaire au cours du vieillissement chez l'homme. Cet article détaillant les recherches récemment conduites à l'INRA met l'accent à la fois sur les principaux mécanismes fondamentaux impliqués et sur les finalités agronomiques et humaines qui en découlent.

\begin{abstract}
Depuis l'identification des mitochondries comme le site principal de la synthèse d'ATP (Adénosine TriPhosphate) et de l'oxydation des substrats dans les années 40 , de multiples aspects du fonctionnement mitochondrial ${ }^{1}$ ont été mis à jour et sont venus souligner le rôle clé de cet organite. Ainsi, l'existence de délétions ou mutations du génome mitochondrial à l'origine des maladies particulièrement graves que constituent certaines cytopathies mitochondriales (dont les myopathies ne constituent que l'exemple le plus médiatisé) a ravivé l'intérêt de la communauté scientifique pour le fonctionnement de ces organites. La démonstration du rôle central des mitochondries dans l'induction de l'apoptose a constitué une véritable révolution, et certaines théories du vieillissement attribuent
\end{abstract}

d'ailleurs un rôle important à une altération progressive de l'activité mitochondriale dans ce phénomène en raison d'une dérégulation de la production de radicaux libres (EAO) et d'une accumulation inéluctable de mutations dans le génome de l'organite. La mise en évidence de récepteurs hormonaux localisés dans la mitochondrie, l'élucidation de leur fonction, et la démonstration de leur implication dans la régulation du métabolisme énergétique et de la différenciation cellulaire (Wrutniak et al 1995, Rochard et al 2000) permet de considérer l'organite comme une cible majeure des hormones thyroïdiennes. Dans ces travaux, l'identification de gènes dont l'expression est modulée par l'activité mitochondriale (myogénine par exemple) établit de manière très claire l'existence d'un dialogue noyau- mitochondries ${ }^{2}$ et souligne l'importance de cette voie d'action. Enfin, la plasticité du fonctionnement mitochondrial au plan énergétique est revenue au premier plan avec la découverte, en 1997, de l'existence d'une famille de gènes codant des protéines découplantes (uncoupling proteins, UCPs) présentes dans de nombreux tissus et dont la fonction exacte reste à clarifier (contrôle de la balance énergétique et de l'adiposité, transport d'acides gras, contrôle de la production de EAO...).

Les mitochondries sont donc potentiellement impliquées dans la régulation de processus physiologiques multiples qui conditionnent le développement et le bon fonctionnement du muscle squelettique : intervention dans

\footnotetext{
${ }^{1}$ Dans ce projet, compte tenu des multiples aspects du fonctionnement mitochondrial, nous utiliserons la dénomination «activité mitochondriale» lorsque l'ensemble des aspects de ce fonctionnement (transcription et traduction mitochondriales, influences sur la signalisation cellulaire via les ROS (Radicaux libres) et le calcium, oxydation des substrats, efficacité de la synthèse d'ATP) sera concerné. La dénomination «activité métabolique» ou «aspects énergétiques» recouvrira spécifiquement l'intervention des mitochondries dans le métabolisme cellulaire.

2 Le dialogue noyau-mitochondries fait référence à la signalisation émanant de EAO ou modifiée par les mitochondries (signalisation calcique) qui va modifier l'expression d'un certain nombre de gènes nucléaires. Parmi ces derniers, figurent des gènes codant des protéines mitochondriales qui, en retour, vont modifier l'activité mitochondriale.
} 
la régulation de la différenciation musculaire et adipocytaire, dans l'acquisition de caractéristiques métaboliques (type de fibres musculaires, teneur en lipides intramusculaires) qui conditionnent les propriétés des viandes (Hocquette et al 1998), dans la gestion des réserves énergétiques qui conditionne le développement respectif des masses adipeuses et musculaires, et enfin dans le processus de fonte musculaire au cours du vieillissement.

Face au renouveau et à l'enjeu actuel de ces recherches, une action collective ciblée sur l'implication des mitochondries dans le développement, la croissance et les propriétés du muscle des animaux d'élevage et dans le déterminisme de la fonte musculaire au cours du vieillissement chez l'homme a été mise en place à l'INRA （www.rennes.inra.fr/mitochondries). L'ensemble des voies métaboliques ou de régulation abordées dans ce travail est rassemblé dans la figure 1. L'objet de cet article est de restituer les principaux résultats obtenus dans ces différents domaines. L'accent est mis à la fois sur les mécanismes fondamentaux élucidés (rôles des facteurs de transcription mitochondriaux, fonctionnement des mitochondries) et sur les finalités agronomiques (différenciation et

Tableau 1. Expression des myosines chez le fœtus de porc (jg : jours de gestation).

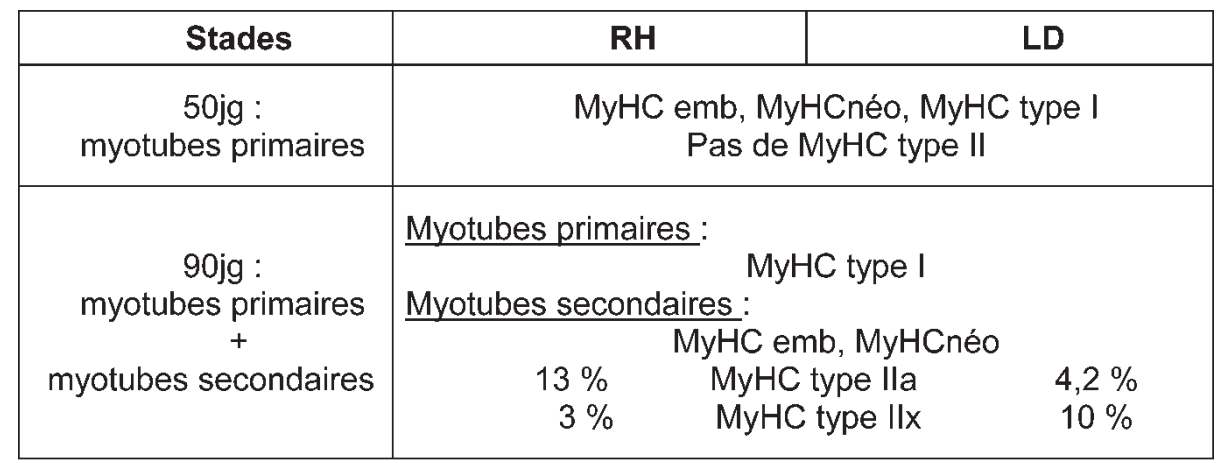

croissance musculaire, qualité des viandes) et humaines (fonte musculaire) qui en découlent.

\section{1 / Fonctionnement mito- chondrial, développement et différenciation muscu- laire}

\section{1 / Contexte et objectifs}

La différenciation contractile caractérisée par le remplacement des isoformes de myosines développementales par les isoformes adultes s'effectue pendant la période fœtale selon une chronologie différente selon les espè- ces, voir encadré (tableau 1 pour le porc). La différenciation métabolique commence également de manière précoce pendant la période fotale. Ces caractéristiques contractiles et métaboliques démontrent cependant une plasticité évidente après la naissance, puisqu'elles sont modulables par des facteurs tels que l'exercice ou la nature de l'alimentation.

La qualité de la viande dépend en grande partie des caractéristiques du muscle au moment de la mort de l'animal. C'est pourquoi, les propriétés des fibres musculaires ont fait l'objet de nombreuses études quelle que soit l'espèce. Nous abordons ici : (i) les relations entre le fonctionnement mitochondrial et les caractéristiques

Figure 1. Quelques rôles physiologiques des mitochondries dans le muscle en rapport avec leurs différentes activités biologiques.

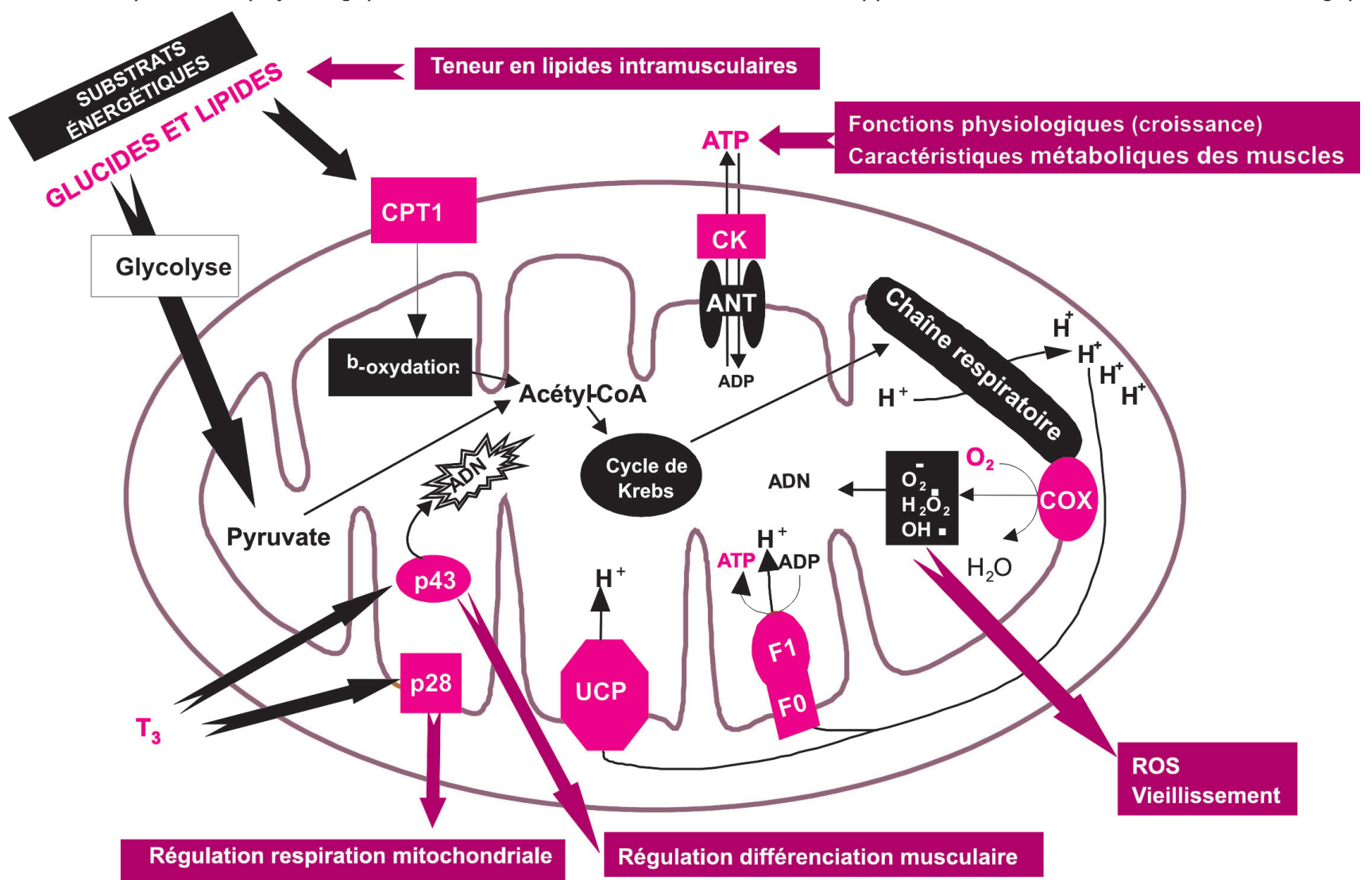




\section{Rappel sur la mise en place des fibres musculaires}

La mise en place et le développement du tissu musculaire résultent d'un ensemble complexe de processus qui interviennent depuis les phases précoces du développement jusqu'au stade adulte. Au cours de la vie fœtale, le déterminisme des lignages cellulaires, la durée de la prolifération et la qualité de la différenciation des myoblastes vont conditionner un paramètre important du développement de ce tissu : le nombre de fibres musculaires. En effet, pour la plupart des espèces animales d'intérêt zootechnique, ce nombre n'évolue plus significativement après la naissance. Chez des espèces à faible maturité telles que le rat, la souris ou le lapin, ce phénomène d'hyperplasie persiste jusqu'au $30^{\mathrm{e}}$ jour de vie postnatale. Les poissons constituent une exception avec l'existence d'un phénomène d'hyperplasie musculaire qui persiste chez les larves après l'éclosion et, pour de nombreuses espèces dont la truite, tout au long de la vie.

Cette mise en place des fibres musculaires s'effectue de manière séquen-

contractiles et métaboliques des fibres musculaires, notamment l'expression des diverses isoformes de myosines (MyHC, chaine lourde de la myosine). Nous avons tout d'abord étudié ces relations en comparant différents types de muscles puis, plus spécifiquement, les différences entre muscles liées au fonctionnement mitochondrial. Les tra- tielle à partir de deux ou trois vagues de myoblastes qui sont à l'origine des différents types de fibres :

- les myoblastes de première génération (myoblastes embryonnaires), présents dès le stade embryonnaire, fusionnent de manière synchrone en myotubes primaires et sont à l'origine des fibres lentes,

- les myoblastes de seconde génération (myoblastes fotaux) apparaissent au cours de la vie fotale et fusionnent de manière asynchrone pour donner des fibres secondaires à la surface de chaque fibre primaire. Les myoblastes fœtaux, pluripotents, fusionnent à la fois avec des myotubes primaires ou secondaires pour former des fibres lentes ou rapides,

- chez les espèces de grande taille (bovin, mouton, homme), une troisième génération de myoblastes de petite taille a été observée. Elle serait à l'origine des fibres IIA chez le bovin. Chez les poissons qui atteignent une grande taille, le recrutement d'autres précurseurs musculaires, situés autour des fibres précédemment formées, contribue à la croissance du myotome jusqu'au stade adulte.

vaux ont été réalisés à des stades précoces importants du développement musculaire définis en fonction du stade d'apparition des fibres primaires et secondaires, puis chez l'animal adulte (bovin, porc, lapin, truite Arc-en-Ciel, tableau 2) ; (ii) l'activité mitochondriale est également à considérer comme un régulateur important de la différenciation des myoblastes, via le contrôle de l'expression de myogénine, un facteur myogénique jouant un rôle clé dans l'induction de la différenciation (Rochard et al 2000). De plus, l'existence d'un dialogue noyau/mitochondries modifiant l'expression de gènes importants pour le développement de ce tissu, posait également la question de la régulation de l'expression des diverses isoformes de myosine par l'activité mitochondriale. Des travaux in vitro ont donc été développés afin de tester une telle hypothèse et d'identifier les bases moléculaires de l'influence myogénique des mitochondries. Ces résultats ont ensuite été testés sur souris transgéniques dont l'activité mitochondriale a été stimulée par surexpression d'un récepteur mitochondrial de la T3 dans le muscle.

\section{2 / Caractéristiques mitochon- driales dans les différents types de fibres}

a) Au cours du développement précoce

Chez le bovin, quel que soit le muscle et le type génétique, le dernier tiers de la gestation est caractérisé par une augmentation de l'activité d'enzymes mitochondriales $\beta$-hydroxy-acyl-CoA deshydrogénase (HAD), Cytochrome-c oxydase (COX) et Isocitrate deshydrogénase (ICDH). Cette évolution est associée à une augmentation des taux circulants d'hormones thyroïdiennes (T3, T4) et d'un de leur dérivé inactif (rT3), de l'activité 5'-désiodase (qui convertit la T4 en T3 et la T3 en T2) et à une diminution de l'expression de la

Tableau 2. Nature des prélèvements effectués dans les diverses espèces.

\begin{tabular}{|c|c|}
\hline Stades étudiés & Muscles testés \\
\hline \multicolumn{2}{|l|}{ BOVIN } \\
\hline $\begin{array}{l}110 \mathrm{j} \text { : prolifération des cellules de } 2^{\text {eme }} \text { génération } \\
150 \mathrm{j} \text { : stade intermédiaire } \\
180 \mathrm{j} \text { : fin de la prolifération } \\
210 \text { et } 260 \mathrm{j} \text { : différenciation contractile } \\
\text { et métabolique } \\
\text { Bœufs de } 23,28 \text { et } 30 \text { mois de différentes races } \\
\text { Taurillons de } 14-19 \text { mois de différentes races }\end{array}$ & $\begin{array}{l}\text { Masseter (MA) : lent / oxydatif } \\
\text { Cutaneus trunci (CT) : rapide / glycolytique } \\
\text { Semitendinosus (ST) : rapide / glycolytique } \\
\text { Rectus abdominis (RA) : mixte / oxydatif } \\
\text { Longissimus thoracis (LT) : mixte }\end{array}$ \\
\hline \multicolumn{2}{|l|}{ PORC } \\
\hline $\begin{array}{l}50 \mathrm{j}: \text { fin de mise en place des myotubes primaires } \\
90 \mathrm{j}: \text { fin de mise en place des myotubes secondaires }\end{array}$ & $\begin{array}{l}\text { Rhomboïdeus }(\mathrm{RH}) \text { : mixte/oxydatif } \\
\text { Longissimus thoracis (LT) : rapide/glycolytique }\end{array}$ \\
\hline \multicolumn{2}{|l|}{ TRUITE ARC-EN-CIEL } \\
\hline $\begin{array}{l}\text { Embryon avant éclosion } \\
\text { Alevins à l'éclosion } \\
\text { Alevins au } 1^{\text {er }} \text { repas, } 30,60,75 \text { et } 90 \mathrm{j} \text { après le } 1^{\text {er }} \text { repas } \\
\text { Juvéniles }\end{array}$ & $\begin{array}{l}\text { Myotome complet (Muscles blanc et rouge) } \\
\text { Muscle blanc et Muscle rouge }\end{array}$ \\
\hline
\end{tabular}


MyHC fotale. Cependant, une corrélation positive entre les taux d'hormones thyroïdiennes et l'activité COX n'a été observée que dans le muscle oxydatif (Cassar-Malek et al 2006, Listrat et al 2001). Compte tenu de l'influence bien établie des hormones thyroïdiennes sur la biogenèse mitochondriale (Wrutniak-Cabello et al 2001), cette observation suggère que, comme chez le Rat (Bahi et al 2005), les muscles glycolytiques ou oxydo-glycolytiques seraient caractérisés par un faible nombre de récepteurs à ces hormones. Par ailleurs, l'activité de certaines enzymes mitochondriales (COX et F0-F1ATPase) est plus faible dans le muscle rectus abdominis (RA) au cours du dernier tiers de gestation (Orzechowski et al 2002), ce qui suppose l'existence d'un retard de différenciation métabolique pour ce muscle dit mixte.

Chez le porc, les mitochondries musculaires semblent également très immatures aux trois quart de la gestation. En effet, leur activité bioénergétique est faible par rapport aux muscles adultes quel que soit le stade et le muscle testés. Il existe cependant des différences de fonctionnement importantes des mitochondries entre les générations de fibres d'une part, et entre muscles d'autre part : i) au stade de 50 jours, avant l'initiation des processus de différenciation contractile, la densité de mitochondries apparaît déjà plus élevée dans les fibres primaires du muscle rhomboideus (RH) (oxydatif) que dans celles du muscle longissimus thoracis) (LT) (glycolytique); ii) au stade 90 jours, les mitochondries des myotubes secondaires du muscle LT montrent une capacité oxydative plus faible que celles du muscle RH. Cette différence est associée à une expression différentielle des MyHC adultes, suggérant une évolution parallèle de la maturation des mitochondries et de l'acquisition des caractéristiques contractiles des myotubes secondaires; iii) on observe une différence marquée de la régulation de la respiration mitochondriale entre les myotubes primaires et secondaires. Ainsi, les mitochondries des myotubes secondaires qui expriment les $\mathrm{MyHC}$ de type II présentent des caractéristiques typiques de celles des fibres rapides glycolytiques IIX (forte affinité pour l'ADP) tandis que la régulation de l'activité mitochondriale dans les myotubes primaires qui expriment la MyHC I est plus proche de celle observée dans les fibres lentes oxydatives (faible affinité pour l'ADP)
(Gueguen et al données non publiées). Ces résultats suggèrent que la mise en place des mécanismes de la régulation mitochondriale s'établirait de façon très précoce, dès la mise en place des myotubes primaires.

\section{b) Chez l'adulte}

- Comparaison des propriétés contractiles et métaboliques entre types de muscles

Chez le bovin, deux muscles ont été étudiés : le rectus abdominis (RA) qui contient environ un tiers de fibres I, IIA et IIB, et le semitendinosus (ST) qui contient beaucoup plus de fibres IIB $(72 \%)$. Dans ces deux muscles, l'activité $\mathrm{LDH}$ est en corrélation négative avec la proportion de MyHC I, alors qu'elle est positivement corrélée avec la proportion de MyHC IIX. La proportion de MyHC I est par ailleurs positivement corrélée avec des indicateurs du métabolisme oxydatif (ARNm FABP-H, activités CS, ICDH et HAD). Parmi les variables étudiées, FABP-H, $\mathrm{ICDH}, \mathrm{COX}, \mathrm{MyHC}$ I, MyHC IIX et LDH sont les indicateurs les plus discriminants du type de muscle (Hocquette et al 2004). La recherche, sans à priori, d'autres indicateurs par comparaison du transcriptome des muscles RA et ST de bovin ne met pas en évidence d'acteurs majeurs du fonctionnement mitochondrial, à l'exception de l'ICDH (ICDH $\beta$-sub-unit precursor) (Sudre et al 2003, 2005).

Les relations négatives entre activités mitochondriales et expression des isoformes rapides des chaînes lourdes de myosine ne sont pas généralisables. En effet, chez la truite arc-enciel, un régime riche en soja et supplémenté en acide glutamique conduit à une augmentation des activités mitochondriales COX et CPT I dans les deux types de muscles axiaux (blanc et rouge) et à une augmentation de l'expression des isoformes des chaînes lourdes de myosine rapides uniquement dans le muscle blanc (AlamiDurante et al 2002). Ce résultat souligne l'importance du facteur de variation étudié et, une fois encore, la réponse spécifique de chaque type de muscle.

- Comparaison du fonctionnement mitochondrial entre types de muscles

Les études sur mitochondries isolées à partir de muscle de porc montrent que la capacité de respiration maximale (état III) est plus élevée pour le muscle RH oxydatif que pour le LT glycoly- tique, alors que la respiration basale (état IV) ne diffère pas. Le couplage oxydation-phosphorylation (RCR) et la synthèse d'ATP sont de ce fait plus importants (x 1,3) dans les mitochondries du RH (x 1,3). Ces différences semblent liées à une capacité d'oxydation des substrats plus importante dans les mitochondries du muscle oxydatif et non à des différences de potentiel de phosphorylation. En effet, l'activité COX est 1,2 fois plus importante dans les mitochondries du RH, tandis que les activités de la F0-F1-ATPase et de la créatine kinase mitochondriale (mi$\mathrm{CK}$ ) sont identiques. Enfin, les mitochondries du LT sont plus sensibles à l'inhibition de la respiration par l'ATP que celles du RH. Ces résultats indiquent que les mitochondries des muscles oxydatif et glycolytique diffèrent dans leurs propriétés fonctionnelles (Gueguen et al 2005a) confirmant et affinant ainsi les observations plus globales réalisées chez le bovin.

Le fonctionnement mitochondrial a ensuite été étudié sur fibres perméabilisées de lapin pour préserver l'environnement cellulaire des mitochondries. Chez cette espèce, il a été possible d'obtenir des fibres homogènes de types I ou IIX, ainsi qu'un mélange de fibres IIA et IIX (appelées arbitrairement IIAX) ou majoritairement IIB (appelées IIB+). La capacité oxydative maximale totale et par mitochondrie s'avère différente entre les différentes catégories de fibres perméabilisées suivant l'ordre I > IIAX $>$ IIX et IIB + . Les fibres I présentent un meilleur couplage oxydation-phosphorylation (RCR) et un Km apparent pour l'ADP beaucoup plus élevé que les types IIX et IIB+, les fibres IIA présentant un Km intermédiaire. Les fibres IIA présentent des caractéristiques plus proches des fibres de type I que de type IIX ou IIB, avec notamment la présence d'un couplage fonctionnel entre l'activation de la mi-CK et la production d'ATP, couplage qui n'apparaît pas dans les fibres IIB ou IIX. De plus, dans les fibres IIA, comme dans les fibres I, la respiration mitochondriale est stimulée en présence de créatine ou d'AMP. De même, l'addition de calcium entraîne une augmentation de la sensibilité mitochondriale à l'ADP dans les fibres I et IIA, cette augmentation étant liée à l'activation des myosines-ATPases par le calcium (Gueguen et al 2005b, 2005c) alors qu'aucune de ces régulations n'est observée dans les fibres IIB ou IIX. Une présentation plus complète de ces résultats est proposée dans un autre article de ce dossier (Gueguen et al 2006). 


\section{Conclusions}

L'ensemble de ces résultats confirme donc l'importance du dernier tiers de la gestation pour la différenciation contractile et métabolique des fibres musculaires. Dans l'espèce bovine, cette période de la vie fotale est caractérisée par une augmentation du métabolisme oxydatif, qui pourrait être sous contrôle des hormones thyroïdiennes au moins pour les muscles oxydatifs. Les résultats obtenus chez le porc indiquent qu'il existe une évolution simultanée de la maturation de l'activité mitochondriale et de l'acquisition des caractéristiques contractiles des fibres musculaires. Ils suggèrent également qu'une différence dans la densité des mitochondries précède l'expression différentielle des myosines dans chaque type de muscle.

Chez l'animal en croissance, le fonctionnement des mitochondries des fibres IIA, bien que rapides, apparaît beaucoup plus proche de celui des fibres lentes I que de celui des fibres rapides IIX et IIB. Ainsi, la régulation de la respiration mitochondriale dans les fibres de types I et IIA est hautement spécialisée avec une optimisation de l'efficacité des mitochondries (couplage entre oxydation et phosphorylation, capacité oxydative maximale) et un couplage fonctionnel entre les kinases mitochondriales et la production d'ATP. Ces couplages supportent un fonctionnement des systèmes créatine et adénylate kinases de type navette permettant, avec la restriction de la sensibilité à l'ADP, un transfert énergétique et une communication efficace entre mitochondries et myosinesATPases. Au contraire, le fonctionnement des mitochondries des fibres IIX et vraisemblablement IIB ne présente pas de régulation particulière, à l'exception d'une forte sensibilité à l'inhibition de la respiration par l'ATP, qui pourrait participer à la régulation de la respiration mitochondriale, et notamment à son inhibition observée dans ces fibres en phase de repos.

\section{3 / L'activité mitochondriale régule la différenciation des myoblastes et l'expression des isoformes de myosines : méca- nismes impliqués}

Parallèlement à leur implication majeure dans le métabolisme énergé- tique, les mitochondries interviennent dans les processus de prolifération et de différenciation cellulaires. Des travaux réalisés à l'INRA ont notamment établi l'importance de l'activité de l'organite dans la régulation de la différenciation des myoblastes, à travers le contrôle de l'expression de myogénine et la capacité des facteurs myogéniques à induire la différenciation (Rochard et al 2000). Dans le but de mieux comprendre les mécanismes impliqués dans la régulation de la différenciation des myoblastes par l'activité mitochondriale, cette étude a été axée sur deux cibles potentielles de l'activité de l'organite : le proto-oncogène $\mathrm{c}-\mathrm{Myc}$ et Calcineurine. Ces cibles avaient été identifiées dans le cadre de travaux préliminaires utilisant notamment la technique de Differential Display.

\section{a) Implication $d u$ proto-oncogène} $c-M y c$

C-Myc est un facteur de transcription impliqué dans l'apoptose, la transformation cellulaire, la prolifération et la différenciation (Henriksson et Luscher 1996). L'inhibition de l'expression de c-Myc est considérée comme un événement majeur survenant au cours de la différenciation de nombreux types cellulaires (Siebenlist et al 1988, Grolli et al 1997, Ryan et Birnie 1997). Inversement, la surexpression de c-Myc inhibe la différenciation terminale des myoblastes (Crescenzi et al 1994, La Rocca et al 1994) à travers un mécanisme impliquant myogénine (Miner et Wold 1991). Ces données bibliographiques ont conduits à étudier l'implication de ce proto-oncogène dans la régulation de la différenciation des myoblastes par l'activité mitochondriale.

Une inhibition de l'activité mitochondriale induite par le chloramphéni$\mathrm{col}^{3}$ abroge l'inhibition de l'expression de c-Myc (ARNm et protéine) qui survient au début de la différenciation terminale des myoblastes. Réciproquement, l'expression de c-Myc est inhibée par une stimulation de l'activité mitochondriale induite par surexpression du récepteur mitochondrial de la T3 (p43) ${ }^{4}$. L'étude de la 1/2 vie des messagers de c-Myc suggère que cette régulation s'exerce à travers des méca- nismes post-transcriptionnels. De plus, l'existence d'un autre niveau de régulation de c-Myc par l'activité de l'organite spécifique à l'espèce aviaire a été établie. En effet, contrairement à c-Myc murin qui présente une localisation nucléaire exclusive, c-Myc aviaire est localisé dans le noyau et dans le cytoplasme. Or, une inhibition de l'activité mitochondriale par le chloramphénicol accroît la fréquence de localisation nucléaire de c-Myc, et par conséquent son activité transcriptionnelle. Une stimulation de l'activité de l'organite par surexpression de la p43 produit les effets inverses. Ces données démontrent donc que, dans l'espèce aviaire, les mitochondries régulent non seulement l'expression de c-Myc, mais également son activité, via une régulation de sa localisation cellulaire

De plus, la surexpression de c-Myc dans les myoblastes reproduit les effets d'une inhibition de l'activité mitochondriale par le chloramphénicol : i) inhibition de la différenciation terminale ; ii) répression de l'expression de myogénine, sans modification de celle de CMD1 (MyoD aviaire); iii) blocage de l'aptitude des facteurs myogéniques (MyoD, myogénine) à induire la différenciation.

Cet ensemble de résultats suggère donc que c-Myc est une cible importante de l'activité mitochondriale impliquée dans l'influence myogénique de l'organite. Cette hypothèse est confortée par les résultats obtenus dans les myoblastes surexprimant la p43. En effet, dans ces cellules, la surexpression de c-Myc compense la diminution de l'expression du gène c-Myc endogène induite par la stimulation de l'activité mitochondriale, et abroge l'influence myogénique de $\mathrm{p} 43$ (Seyer et al 2006a).

Enfin, l'activité mitochondriale cible préférentiellement les cellules prolifératives. Des analyses du cycle cellulaire montrent que la fréquence des myoblastes en G0-G1 à confluence cellulaire est augmentée par surexpression de p43 et diminuée par le chloramphénicol ou la surexpression de c-Myc (Seyer et al 2006a). Ces résultats indiquent que la sortie irréversible des myoblastes du cycle cellulaire, prérequis majeur pour la différenciation ter-

\footnotetext{
${ }^{3}$ Cet antibiotique bloque la synthèse protéique spécifique de la mitochondrie, ce qui inhibe l'activité de 4 des 5 complexes de la chaîne respiratoire qui comprennent des sous-unités codées par le génome mitochondrial.

${ }^{4}$ p43 est une forme tronquée d'un récepteur nucléaire de la T3, spécifiquement adressée dans les mitochondries. Il s'agit d'un facteur de transcription du génome mitochondrial qui stimule l'expression des protéines codées par ce génome, l'activité de la chaîne respiratoire et la mitochondriogenèse (Wrutniak et al 1995, Casas et al 1999).
} 
minale, est une cible de l'activité mitochondriale via le contrôle de l'expression de c-Myc.

\section{b) Implication de la Calcineurine}

Calcineurine est une phosphatase calcium dépendante impliquée dans la signalisation calcique qui semble intervenir dans la régulation de la différenciation musculaire (Semsarian et al 1999, Friday et al 2000), en particulier de la différenciation contractile (Chin et al 1998, Delling et al 2000).

Or, 1'expression de Calcineurine (ARNm et protéine) est diminuée au cours de la différenciation des myoblastes par une inhibition de l'activité mitochondriale, induite par le chloramphénicol, ou par la surexpression de c-Myc. Réciproquement, la surexpression de la p43 accroît son niveau d'expression. Ces données démontrent donc que l'expression de Calcineurine est régulée par l'activité mitochondriale ; ils suggèrent également que cette régulation s'exerce à nouveau via le contrôle de c-Myc (Seyer 2005).

Par ailleurs, la surexpression d'une forme constitutivement active de Calcineurine dans les myoblastes aviaires QM7 ou murins $\mathrm{C}_{2} \mathrm{C}_{12}$, induit une forte stimulation de la différenciation associée à une augmentation de l'expression de myogénine. Réciproquement, la surexpression stable d'un messager antisens de Calcineurine dans des myoblastes $\mathrm{C}_{2} \mathrm{C}_{12}$ induit une forte diminution du niveau de la protéine et une inhibition complète de la différenciation, associée à l'extinction de l'expression de myogénine. Ces résultats démontrent donc que, via le contrôle de l'expression de c-Myc, l'activité mitochondriale régule l'expression de Calcineurine. Cette phosphatase calcium dépendante régule à son tour l'expression de myogénine et la différenciation des myoblastes (Seyer 2005).

L'expression de Calcineurine a été associée à l'acquisition d'un type contractile lent par les fibres musculaires (Chin et al 1998). Ceci suggérait donc que l'activité mitochondriale, en contrôlant l'expression de Calcineurine, intervenait dans l'acquisition des caractéristiques contractiles des fibres musculaires. Une telle hypothèse expliquerait l'association métabolisme oxydatif/type contractile lent. En accord avec cette hypothèse, la surexpression de Calcineurine ou de p43 accroît très fortement l'expression des myosines lentes (figures 2 et 3), au détriment des myosines rapides, dans les myo-

Figure 2. Myoblastes aviaires en culture. La stimulation de l'activité mitochondriale par surexpression de p43 stimule très fortement la différenciation des myoblastes, y compris lorsqu'elle est fortement réprimée par la présence de fortes concentrations de sérum dans le milieu de culture.

Immunofluorescence : anticorps dirigé contre la connectine (protéine spécifique du muscle).

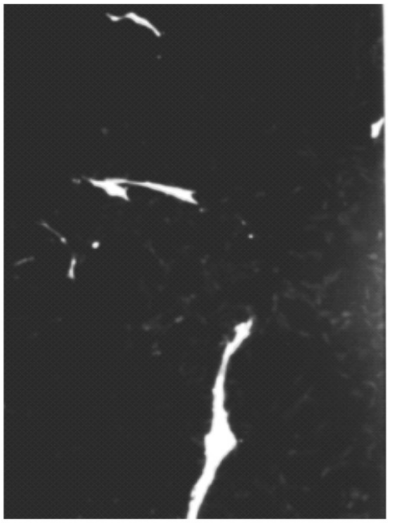

Témoins

blastes murins de la lignée $\mathrm{C}_{2} \mathrm{C}_{12}$. Ces données démontrent donc que l'expression des isoformes de myosine dans les myoblastes en culture est contrôlée par la voie d'action mitochondriale de la T3, et plus généralement par l'activité mitochondriale (Seyer 2005).

c) Validation par transgenèse des relations activité mitochondrialel caractéristiques contractiles des fibres musculaires

Dans le but de mieux comprendre l'influence d'une stimulation de l'activité mitochondriale sur le développement musculaire, des souris transgéniques qui surexpriment le récepteur mitochondrial de la T3 (p43) spécifiquement dans le muscle ont été géné-

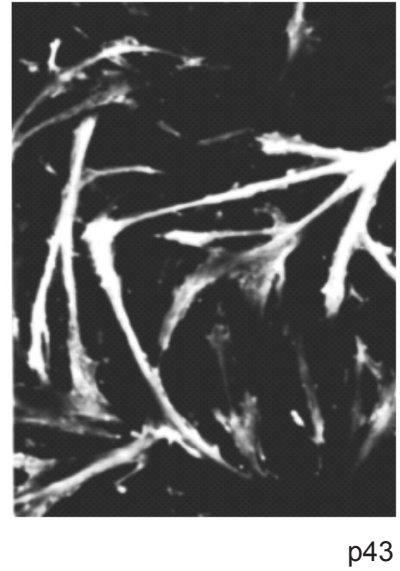

rées. Le transgène a été introduit dans un vecteur d'expression sous contrôle du promoteur de l' $\alpha$-actine squelettique humaine. En accord avec les précédentes études utilisant le même promoteur (Brennan et Hardeman 1993), la p43 est spécifiquement surexprimée dans le muscle squelettique de souris. Sur mitochondries isolées, une surexpression maximale de la p43 d'un facteur 6 est observée selon les lignées de souris.

Le phénotypage des animaux est actuellement en cours mais des résultats particulièrement intéressants ont déjà été obtenus. Ainsi, chez les souris âgées de 2 mois, l'étude de différents muscles (Gastrocnemius, Tibialis et Soleus) indique que la surexpression de la p43 entraîne une augmentation de l'activité mitochondriale (activités de

Figure 3. Myoblastes murins en culture. La stimulation de l'activité mitochondriale par surexpression de p43 stimule très fortement la l'expression de myosine lente. L'image est prise à indice de fusion équivalent (Témoins : 4 jours de différenciation ; $p 43: 2$ jours de différenciation).

Immunofluorescence : anticorps dirigé contre la MyHC lente (Seyer et al en préparation).

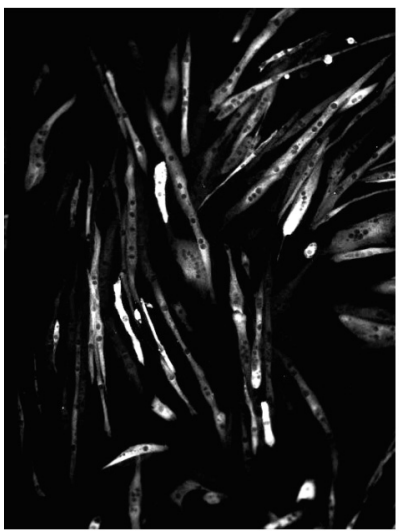

Témoins

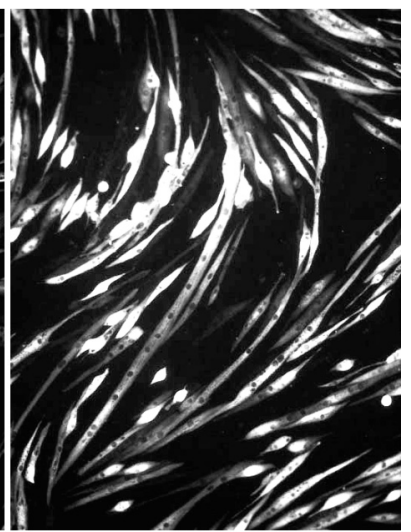

p43 
la succinate déshydrogénase (SDH) et de la COX). Par ailleurs, des gels d'électrophorèse et des expériences d'immunohistochimie réalisées avec des anticorps dirigés contre les chaînes lourdes de myosine (I, IIa, IIa+IIb), montrent une modification des caractéristiques contractiles, avec notamment, dans le Gastrocnemius, une augmentation importante du nombre de fibres de type IIA associée à une diminution du nombre des fibres de type IIB. Ces données valident donc les résultats obtenus sur cultures de myoblastes (Casas et al 2006). En parallèle, une invalidation de la p43 a été réalisée pour compléter l'interprétation de ces résultats. Les premières souris homozygotes $\mathrm{p} 43-/-$ obtenues sont en cours de phénotypage.

\section{Conclusions}

Cette étude démontre l'existence d'un dialogue mitochondries-noyau, non seulement impliqué dans la biogenèse mitochondriale, mais également dans le contrôle de gènes importants du développement musculaire. Elle a également permis d'établir que la voie d'action mitochondriale de la T3 est impliquée dans la régulation de la différenciation des myoblastes.

Le contrôle de l'expression du protooncogène c-Myc constitue un élément essentiel de cette influence myogénique. En effet, c-Myc module l'expression de deux régulateurs de la différenciation des myoblastes : myogénine et Calcineurine. Cette phosphatase calcium-dépendante est impliquée dans l'acquisition du phénotype lent par les fibres musculaires. Un tel mécanisme permet à l'activité mitochondriale, à la fois in vivo et in vitro d'orienter la nature contractile du type de fibres (figure 4). Ces données, validées in vivo sur souris transgéniques, apportent une explication à l'association observée chez le porc, le bovin et le lapin entre activité mitochondriale et type de fibre. Elles démontrent également toute l'importance de la voie d'action mitochondriale de la T3 dans les processus du développement musculaire.

\section{4 / Conclusions sur les rela- tions entre activité mitochon- driale et mise en place des fibres musculaires.}

Quelle que soit l'espèce étudiée il semble que l'activité mitochondriale musculaire soit relativement immature au cours des stades précoces du développement. Les résultats obtenus chez le bovin suggèrent que l'augmentation

Figure 4. Implication de la voie d'action mitochondriale de la T3 dans la différenciation musculaire et l'acquisition des caractéristiques contractiles.

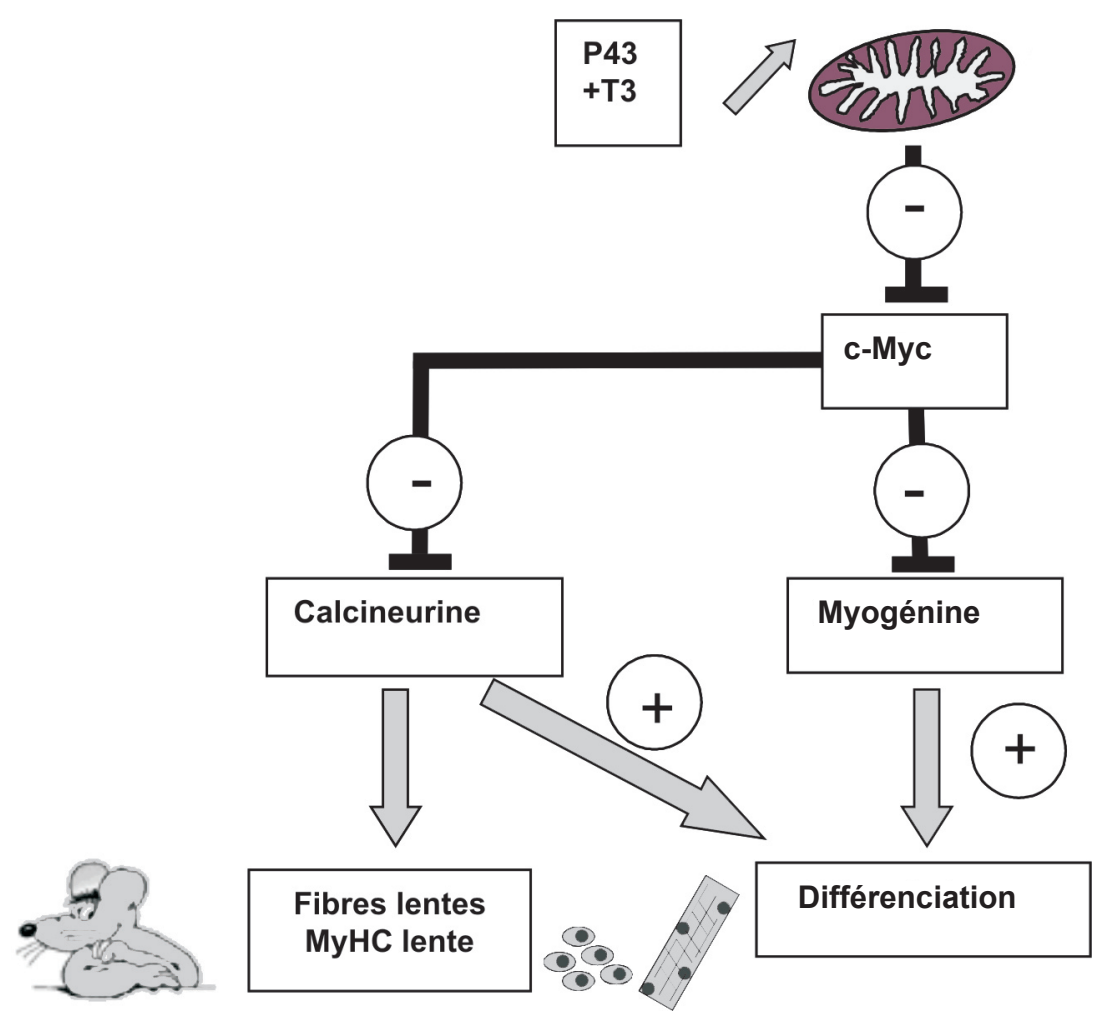

Le proto-oncogène c-Myc inhibe l'expression de Myogénine et de Calcineurine. Via la p43, la T3 stimule l'activité mitochondriale et réduit l'expression de c-Myc. En conséquence, l'expression accrue de Calcineurine et surtout de myogénine stimule la différenciation des myoblastes. De plus, Calcineurine oriente la différenciation contractile vers le type lent. Ces données expliquent notamment l'association type métabolique oxydatif (activité mitochondriale importante)/type contractile lent. Ces données sont en accord avec les résultats in vivo obtenus sur les souris surexprimant la p43 dans le muscle squelettique.

de l'activité mitochondriale qui survient au cours du dernier tiers de la gestation puisse être induite par l'évolution simultanée des taux circulants d'hormones thyroïdiennes, au moins dans les muscles oxydatifs. Les résultats obtenus chez le porc mettent par ailleurs en évidence une évolution parallèle de l'activité mitochondriale et de l'acquisition des caractéristiques contractiles des fibres musculaires. Ils suggèrent, de plus, qu'une différence dans la densité mitochondriale au niveau des fibres primaires précède le déterminisme du type contractile des fibres. Les données obtenues in vitro ou sur souris transgéniques démontrent que l'activité mitochondriale des myoblastes est un régulateur important de la différenciation musculaire ; de plus, elle est impliquée dans le déterminisme $\mathrm{du}$ type contractile des fibres. Ces résultats, en accord avec les observations sur la densité mitochondriale chez le fœetus de porc en développement expliquent de manière satisfaisante l'association métabolisme oxydatif/ type contractile lent observé dans les fibres musculaires. Une partie des mécanismes impliqués a été élucidée avec l'intervention du proto-oncogène c-Myc qui régule l'expression de Calcineurine et myogénine. Par ailleurs, les travaux sur la voie d'action mitochondriale de la T3 confirment son importance pour le développement musculaire, et sont en accord avec les résultats associant la maturation des mitochondries musculaires à une évolution de l'activité thyroïdienne observée chez le bovin.

Chez le bovin adulte, les enzymes mitochondriales ICDH et $\mathrm{COX}$ font partie des indicateurs les plus discriminants du type de fibres ; l'analyse du fonctionnement mitochondrial sur fibres isolées suggère par ailleurs que l'activité mi-CK (ou le rapport mi$\mathrm{CK} / \mathrm{CK}$ totale) serait un indicateur pertinent. Chez le porc et le lapin, l'ensemble des résultats acquis indique que les différents types de fibres musculaires diffèrent non seulement par leur densité mitochondriale, mais aussi par la nature intrinsèque des mitochondries dont l'activité et la régulation sont significativement différentes. En particulier, les différences observées sont en parfait accord avec l'inhibition de l'ac- 
tivité respiratoire mitochondriale dans les fibres rapides au repos, tandis que les fibres IIA, bien que classées parmi les rapides, ont un fonctionnement mitochondrial très proche des fibres lentes.

\section{2 / Rôle des mitochondries dans le déterminisme de la teneur en lipides intramus- culaires}

\section{1 / Contexte et objectifs}

La connaissance et la maîtrise du déterminisme de la teneur en lipides intramusculaires (LIM), paramètre essentiel de la jutosité et de la flaveur de la viande (Touraille 1994), est un objectif important en production animale. Les muscles les plus oxydatifs (les plus riches en mitochondries) semblent contenir plus de lipides mais cette relation est loin d'être généralisable et la teneur en LIM pourrait plus probablement être la résultante d'un équilibre entre les différentes voies du métabolisme des lipides dans le muscle (capture, dépôt, synthèse, lipolyse, oxydation). Nous avons donc tenté d'apprécier l'importance respective de ces différentes voies, et notamment de l'oxydation mitochondriale des acides gras et de l'activité de la carnitine palmitoyl transférase 1 (CPT 1), dans les variations de la teneur en LIM de différentes espèces animales et dans différents muscles. Nous nous sommes ensuite attachés à préciser si une modification de l'oxydation mitochondriale par les facteurs d'élevage s'accompagnait d'un changement concomitant des teneurs en LIM.

\section{2 / Relations entre l'activité mitochondriale et la teneur en lipides intramusculaires}

D’une façon générale, l'exploitation de la variabilité des teneurs en LIM entre muscles, entre génotypes ou en fonction de l'âge montre que, au même titre que le potentiel de synthèse ou de transport des acides gras, le potentiel d'oxydation des acides gras et la teneur en LIM sont corrélés positivement ( $r=0,60$ chez le porc et le bovin). En effet, lorsque l'on compare des muscles de types métaboliques différents intra ou inter-races, chez le bovin (Hocquette et al 2003a) et le lapin (Gondret et al 2004), les muscles les plus riches en lipides possèdent les potentiels d'oxydation mitochondriale, de synthèse et de transport des acides gras les plus importants. Différents muscles oxydatifs ou glycolytiques ont été étudiés chez des bœufs et des taurillons de race Angus (grasse), Limousine (maigre) (figure 5) et/ou Blanc Bleu Belge (très maigre) (Bultot et al 2002, Hocquette et al 2002). Les activités enzymatiques mesurées permettent de classer les échantillons musculaires du plus oxydatif au plus glycolytique, c'est-à-dire dans l'ordre décroissant des teneurs en LIM. De plus, en race Charolaise, la sélection génétique favorisant la croissance musculaire s'accompagne d'une diminution du métabolisme oxydatif concomitante à une diminution des teneurs en LIM (Hocquette et al 2004). Chez la truite et chez le porc, l'activité CPT1 est plus élevée dans les muscles rouges très riches en lipides que dans les muscles blancs pauvres en lipides et dont le potentiel de $\beta$-oxydation est faible (Schmidt et Herpin 1997, Herpin et al 2003, Gutières et al 2003). Ces résultats suggèrent que la teneur en LIM est davantage corrélée avec l'importance des flux de lipides dans le muscle (turnover) qu'avec une voie métabolique particulière. Chez le lapin, cette conclusion est d'ailleurs confortée par les résultats d'une analyse en composantes principales (Gondret et al 2004).

Figure 5. Caractéristiques biochimiques [teneurs en triglycérides] et métaboliques [activités de la lactate déshydrogénase ( $L D H)$, de la phosphofructokinase (PFK), de la lipoprotéine lipase (LPL), de la citrate synthase (CS), de la $\beta$-hydroxy-acyl-CoA déshydrogénase (HAD), de l'isocitrate déshydrogénase (ICDH) et de la cytochrome-c oxydase (COX), teneur en Fatty Acid Binding Protein des Adipocytes (FABP-A)] du muscle Longissimus thoracis de bœufs Limousins (produisant une viande maigre) et de bœufs Angus (produisant une viande grasse). Les résultats des activités enzymatiques sont exprimés par mg de protéines et les résultats sont rapportés en valeurs centrées par rapport à 1 (adapté de Hocquette et al 2003a).

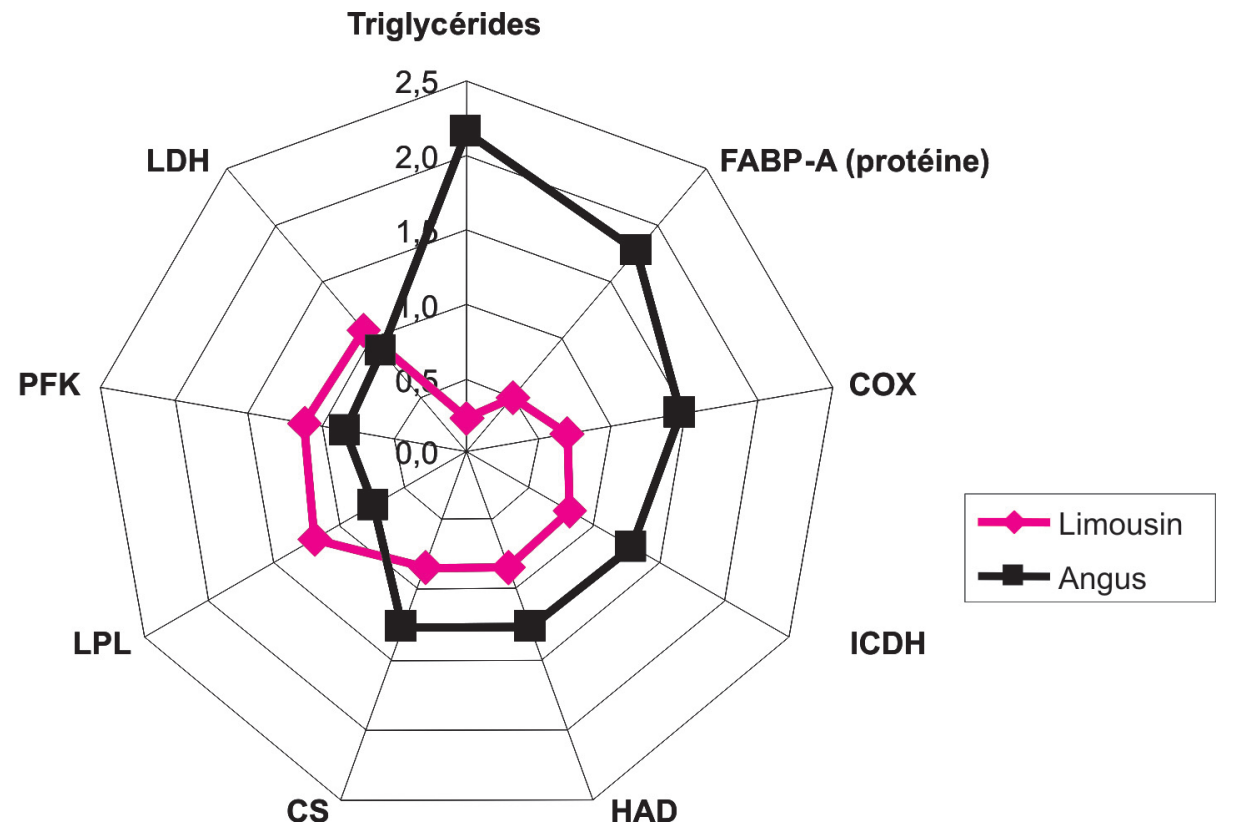




\section{3 / Régulation de la teneur en LIM et de l'activité mitochon- driale par les facteurs d'élevage}

Par cette approche, nous voulions déterminer si les facteurs d'élevage régulent de façon concomitante 1'activité mitochondriale et la teneur en LIM.

Chez le bœuf, l'apport d'huile de tournesol ou de lin (riches en lipides polyinsaturés) par infusion dans le duodénum modifie l'activité métabolique des muscles (augmentation du potentiel de $\beta$-oxydation, diminution des potentiels d'utilisation du glucose et de la chaîne respiratoire) sans modifier les teneurs en LIM (Bouhraoua et al 2001). Par ailleurs, le muscle RA de bœufs au pâturage (régime à base d'herbe avec déplacement) présente des activités mitochondriales supérieures à ceux alimentés à l'auge avec un régime à base d'ensilage de maïs (Listrat et al 2001) alors que les teneurs en LIM sont comparables. Il s'avère que l'augmentation des activités citrate synthase (CS) et HAD au pâturage est sans doute davantage liée à l'activité physique des animaux qu'au régime alimentaire (Jurie et al 2006).

Chez le poisson, la teneur en LIM du muscle blanc et du muscle rouge augmente avec le taux de lipides de l'aliment, mais aucune modification de l'activité CPT1 et de sa régulation par le malonyl-CoA n'est observée dans les tissus musculaires. La nature des acides gras du régime ne modifie pas significativement l'activité CPT1 des muscles (cardiaque, blanc et rouge), les capacités d'oxydation du palmitate et les teneurs en LIM de ces tissus. En revanche, le remplacement de la farine de poisson dans l'alimentation de la truite par du soja riche en phytoestrogènes qui perturbe la prise alimentaire et le métabolisme, stimule l'activité de la CPT1 dans tous les tissus (effet particulièrement marqué dans le muscle rouge) alors que le remplacement de la farine de poisson par un mélange de sources protéiques excluant le soja (gluten de blé, de maïs, farines de pois extrudé et de colza) tend à diminuer les capacités oxydatives des muscles. L'ensemble des résultats obtenus indique que l'activité CPT1 dans les tissus musculaires de la truite arc-en-ciel est faiblement régulée par les nutriments. En revanche, l'activité CPT1 est stimulée dans les situations où la demande énergétique est accrue (jeune, régime déséquilibré par rapport aux besoins).
Cette stimulation de l'activité correspond à une expression accrue des isoformes A et B. En effet, 4 isoformes de CPT1 ont été identifiées chez la truite, leur expression est ubiquitaire à l'exception de l'isoforme D dont l'expression dans les tissus musculaires n'est détectable que dans les stades précoces (Gutières 2003).

Enfin, chez le mini-porc, la consommation d'un régime riche en lipides et en glucides à haut niveau glycémique, augmente légèrement la teneur en LIM et s'accompagne d'une réduction du niveau d'ARNm de la CPT1 sans modification du potentiel maximal d'activité de la $\mathrm{CS}$ et de la HAD (Guillerm-Regost et al sous presse).

\section{4 / Conclusion}

L'activité mitochondriale n'apparaît pas toujours comme un déterminant majeur de la teneur en LIM. Dans les comparaisons entre types de muscles, la teneur en LIM est davantage corrélée avec l'importance des flux de lipides dans le muscle (turnover) qu'avec une voie métabolique particulière, alors que pour certains génotypes particuliers, certains facteurs non mitochondriaux comme la teneur en FABP-A apparaissent déterminants. Les manipulations nutritionnelles n'apportent pas davantage d'éléments permettant de relier clairement activité mitochondriale et teneur en LIM.

Figure 6. Fonctionnement de la chaîne respiratoire.

\section{Energétique mitochondriale}

cytosol

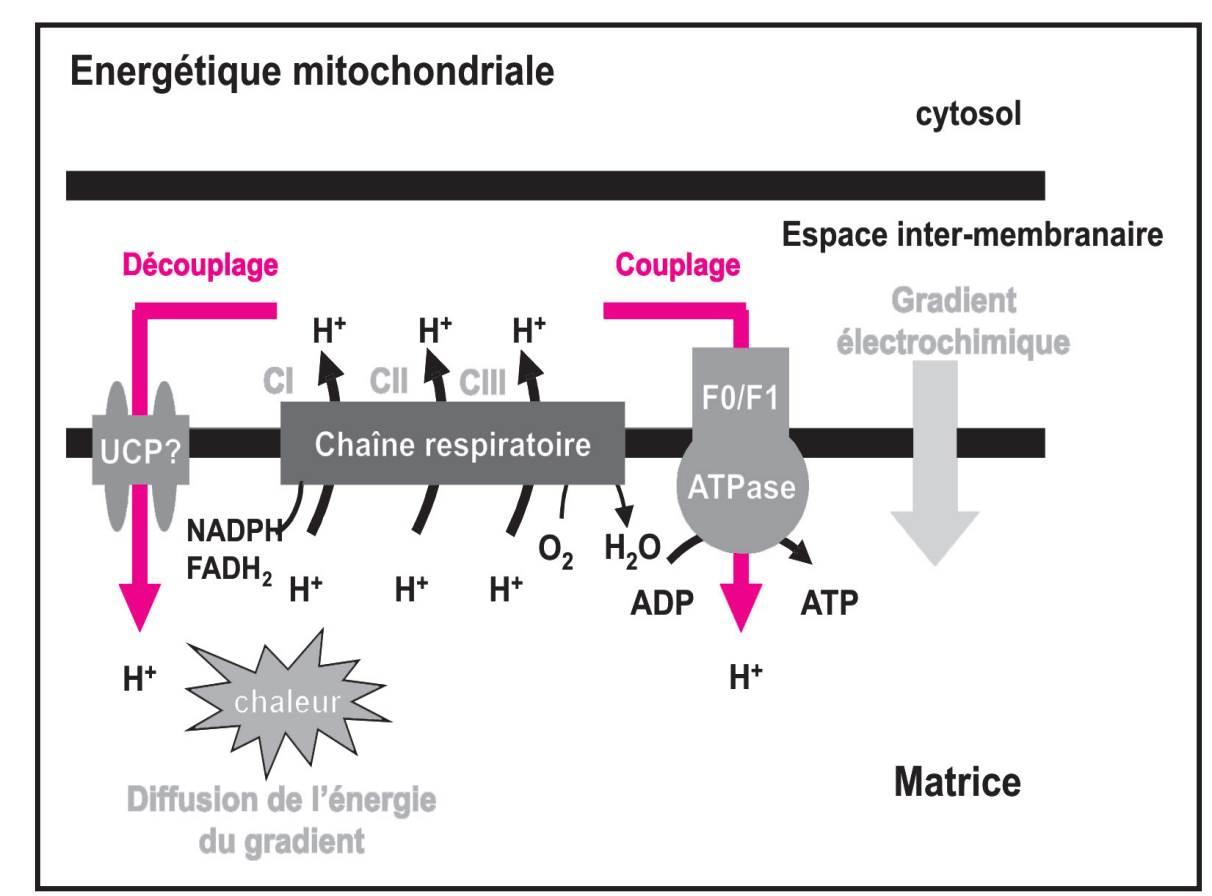

\section{3 / Implication des protéi- nes découplantes (UCP2, UCP3 et UCP aviaire) dans le contrôle du métabolisme énergétique et lipidique}

\section{1 / Contexte et objectifs}

Les protéines découplantes (UCP) sont des protéines mitochondriales qui diminuent la synthèse d'ATP associée à l'oxydation des substrats énergétiques (figure 6). Elles appartiennent à une famille de gènes initialement mise en évidence dans le Tissu Adipeux Brun (TAB). Le rôle thermogènique $\mathrm{de}$ l'UCP1 (spécifique du TAB) est clairement établi depuis longtemps (production de chaleur par dissipation du gradient électrochimique de protons au niveau de la membrane mitochondriale interne). Mais la découverte en 1997 et 1998 de trois nouveaux membres s'exprimant dans de nombreux autres tissus (UCP2, protéine ubiquitaire, UCP3 et UCP4 spécifiques respectivement du tissu musculaire et du cerveau) a renforcé l'intérêt pour ces protéines qui semblent posséder la même activité biologique et pourraient jouer un rôle clé dans le contrôle du métabolisme basal et des dépenses énergétiques (Rolfe et Brand 1996, Rousset et al 2004). Cependant, les mécanismes mis en jeu sont encore controversés (Hesselink et al 2003) et la fonction 
physiologique de ces protéines reste à identifier : rôle thermogénique, rôle anti-obésité, transport d'acides gras, prévention contre la production de radicaux libres?

Après avoir démontré la présence de ces protéines chez des espèces de rente dépourvues de TAB, le porc (présence des UCP2 et UCP3, Damon et al 2000) et l'oiseau (existence d'une avUCP, Raimbault et al 2001), nous nous sommes attachés à décrire leur expression au cours du développement et à tenter de préciser leur rôle dans le métabolisme énergétique et lipidique musculaire.

\section{2 / Expression des UCPs dans le muscle au cours du dévelop- pement}

Chez le porc, comme chez les autres mammifères, l'UCP3 n'est pas exprimée au cours de la période fœtale. En revanche, elle est fortement induite à la naissance puis le taux d'ARNm diminue à 5 jours pour atteindre le niveau d'expression de l'adulte. L'UCP2 en revanche est primée au cours de la période fœtale dès le stade myotube primaire et son expression est alors plus importante dans un muscle LT glycolytique que dans un muscle RH oxydatif. En revanche à la naissance le niveau d'expression d'UCP2 diminue et n'est plus modifié jusqu'au stade d'abattage $(100 \mathrm{~kg})$. Si l'induction de l'expression d'UCP3 à la naissance a été corrélée à la transition d'un régime alimentaire fotal riche en glucides vers une alimentation lactée riche en lipides (Brun et al 1999), la fonctionnalité et le rôle d'UCP2 dans le muscle fœtal reste à démontrer.

Par ailleurs, chez les mammifères, on observe généralement une expression préférentielle des UCPs dans les muscles glycolytiques et oxydo-glycolytiques par rapport aux muscles oxydatifs. Nous ne retrouvons pas ce résultat chez le porc, en accord avec la mesure d'un potentiel de membrane identique dans les muscles LT et RH (Damon et al 2000). Chez le poulet nourri, l'expression d'avUCP varie en revanche en fonction du type métabolique du muscle (mixte>glycolytique $>$ oxydatif, Cassy et al 2005). Cette expression majoritaire dans les muscles mixtes chez l'oiseau pourrait leur conférer une meilleure flexibilité vis-à-vis de l'utilisation des ressources énergétiques disponibles (glucides versus lipides). La question de l'expression différentielle des UCPs en fonction du type de fibre reste donc largement ouverte.

\section{3 / Implication des UCPs dans le contrôle du métabolisme éner- gétique}

Différentes situations physiologiques connues pour moduler l'intensité du métabolisme énergétique ont été comparées pour tenter d'obtenir une première indication sur l'implication éventuelle des UCPs.

Chez le porc, les UCPs ne semblent pas être impliquées dans les réponses adaptatives à l'environnement thermique. Comme cela est rapporté pour d'autres mammifères (Ricquier 2005), nous n'observons pas de modification de l'expression des UCPs dans le muscle en réponse au froid (stress froid de $4 \mathrm{~h}$ chez le nouveau-né, très sensible au froid). Une exposition au chaud ne modifie pas davantage l'expression des UCP2 et UCP3 dans le muscle (Damon communication personnelle). Ce résultat tranche d'ailleurs avec l'induction de l'expression d'UCP3 observée par Katsumata et al (2004) dans les muscles de porcs élevés au chaud. En revanche, nos résultats suggèrent que les UCPs pourraient intervenir dans le contrôle du métabolisme basal. Ainsi, la comparaison de porcelets chinois de race Meishan, plus matures au plan physiologique et en termes de métabolisme énergétique à la naissance, avec des porcelets de génotypes conventionnels montre que ces animaux possèdent à la fois un métabolisme basal supérieur et une expression d'UCP3 supérieure dans le muscle Rhomboïde et le tissu adipeux (Herpin et al 2004).

La réponse des UCPs musculaires aux modifications de l'environnement thermique semble différente et plus claire chez les oiseaux. En effet, des poulets exposés à un froid modéré $\left(20 v s 29^{\circ} \mathrm{C}\right)$ pendant 7 jours présentent une thermogenèse plus élevée $(+83 \%)$ qui s'accompagne d'une augmentation de $20 \%$ de l'expression d'avUCP (Collin et al 2003a). A l'inverse, un conditionnement précoce au chaud diminue fortement l'expression d'avUCP (- $85 \%$, Taouis et al 2002), un résultat confirmé dans une étude plus récente menée sur des poussins de trois jours conditionnés ou non à la chaleur pendant l'embryogenèse (Collin communication personnelle). Toujours chez les oiseaux, il nous a paru intéressant de comparer l'expression d'avUCP dans les lignées divergentes sélectionnées sur l'efficacité alimentaire (indice de consommation). Cependant, bien qu'elles présentent des différences marquées au plan du méta- bolisme lipidique et de l'efficacité énergétique, ces deux lignées ne différent pas pour l'expression d'avUCP, quel que soit le type métabolique de muscle étudié (Cassy et al 2005).

Enfin, l'effet de l'activité physique sur l'expression protéique d'UCP3 dans le muscle a été étudié sur des homogénats musculaires de 2 lots de lapins ayant été soumis à un exercice physique répété (saut) ou sédentaires. Aucune modification du contenu en UCP3 n'a ici été mise en évidence en dépit d'une meilleure aptitude du muscle à oxyder les acides gras.

\section{4 / Régulation hormonale des UCPs}

La triiodothyronine (T3), hormone thermogénique modifiant la conductance membranaire des mitochondries chez les Mammifères et les Oiseaux (Rousset et al 2004), est connue pour stimuler la dépense énergétique. Chez le rat, l'UCP3 serait la cible moléculaire principale de la T3 avec une induction d'un facteur 25 de son niveau d'expression dans le muscle (De Lange et al 2001). Nous confirmons ce résultat dans les espèces de rente. Ainsi, chez le poulet l'expression moléculaire d'avUCP double dans le muscle gastrocnémien d'animaux hyperthyroïdiens (régime supplémenté en T3), et est fortement inhibée chez les poulets recevant l'inhibiteur thyroïdien méthimazole (Collin et al 2003b). En revanche, une injection d'insuline $(8 \mathrm{u} / \mathrm{kgPV} / \mathrm{j})$ pendant 5 jours ne modifie pas l'expression d'avUCP dans le muscle.

Chez le porc, l'induction des ARNm UCP3 par un traitement aigu avec des doses supra physiologiques $(250 \mu \mathrm{g} / \mathrm{kg} / \mathrm{j})$ de T3 est plus importante dans le muscle LT glycolytique que dans le muscle RH oxydatif (Damon et al 2000). Ce résultat est conforté par des données montrant qu'un traitement chronique de 7 jours avec des doses plus physiologiques $(40 \mu \mathrm{g} / \mathrm{kg} / \mathrm{j})$ de T3 induit l'expression d'UCP3 (facteur 4-5) dans le muscle LT mais pas dans le RH. En parallèle, le métabolisme basal des animaux augmente, la respiration des mitochondries isolées du muscle LT augmente de $15 \%$ et leur potentiel de membrane diminue, indiquant une augmentation des fuites de protons chez les animaux traités T3. Comme dans les études antérieures, l'expression basale du gène UCP3 est cependant très faible et l'effet de la T3 semble beaucoup moins important que 
chez le rat (facteur 5 versus facteur 25). Ces traitements n'ont en revanche pas d'effet sur 1'expression du gène UCP2 et ceci quel que soit le muscle étudié. A travers son rôle dans le contrôle des fuites de protons, l'UCP3 semble donc jouer un rôle clé dans la réponse du muscle à la T3, un effet qui dépend du type métabolique et contractile des muscles.

\section{5 / Implication des UCPs dans le métabolisme lipidique}

Les données bibliographiques suggèrent une implication des UCPs dans le métabolisme (transport intra membranaire) des acides gras (Dulloo 2004) et une approche positionnelle a montré que les locus des gènes UCP2 et UCP3 coïncident avec des QTLs marqueurs de l'obésité. Nous avons donc recherché l'existence d'un lien éventuel avec le métabolisme lipidique.

En utilisant les lignées divergentes de poulet maigres ou grasses, nous montrons que l'expression d'avUCP est fortement corrélée avec l'expression du gène de la CPT1 musculaire. De plus l'expression d'avUCP est accrue de $30 \%$ chez les poulets «gras», qui semblent avoir un turnover lipidique plus important que les poulets du génotype «maigre». Cet effet est accentué chez les poulets recevant un régime enrichi en lipides (Collin communication personnelle). Ces variations corrélatives suggèrent effectivement une relation entre avUCP et métabolisme lipidique. Mais cette relation est loin d'être univoque. En effet, Schrauwen et al (2003) ont montré que l'inhibition de la CPT1

Tableau 3. Synthèse sur les facteurs de variation de l'expression des UCPS dans le muscle de poulet (av UCP) et de porc (UCP2 et UCP3).

\begin{tabular}{|c|c|c|c|}
\hline $\begin{array}{l}\text { Facteurs } \\
\text { de variation }\end{array}$ & Av UCP & UCP3 & UCP2 \\
\hline Froid & $\pi$ & $\rightarrow$ & $\rightarrow$ \\
\hline Chaud & $y$ & $\rightarrow$ & ND \\
\hline Métabolisme basal & ND & $\pi$ & $\rightarrow$ \\
\hline Exercice & ND & $\rightarrow$ & ND \\
\hline T3 & $\pi$ & $\pi$ & $\rightarrow$ \\
\hline Ins & $\rightarrow$ & ND & ND \\
\hline Oxydation des lipides & $\pi$ & $\rightarrow$ & $\rightarrow$ ou $\lambda$ \\
\hline Efficacité alimentaire & $\rightarrow$ & ND & ND \\
\hline Type métabolique des muscles & Glycolytique & $\rightarrow$ & $\rightarrow$ \\
\hline
\end{tabular}

$\mathbf{y}$ : inhibition ;

: induction : augmente l'expression de la protéine UCP3 dans le muscle de rat. Par ailleurs, nous montrons que l'expression des gènes UCP3 et UCP2 dans les muscles LT et RH de porcs croisés LW $x$ Duroc sélectionnés sur la base de leurs teneurs (haute ou basse) en lipides du muscle (cf partie 2) ne diffère pas, aucune corrélation entre l'expression d'UCP2 ou d'UCP3 et l'oxydation des acides gras ne pouvant être mise en évidence. Enfin, chez des mini porcs Yucatan ayant reçu un régime hyper énergétique l'expression de la lipase hormono-sensible (enzyme clé de la lipolyse), de la CPT1 ou de l'UCP2 sont sensiblement diminuées par rapport aux porcs témoins, alors que l'UCP3 est inchangée. Cette diminution du catabolisme lipidique est aussi associée à une réduction de la sensibilité à l'insuline du muscle squelettique chez le mini porc (Guillerm Regost et al 2006 sous presse).

\section{6 / Conclusion}

Nous montrons que UCP2, UCP3 et avUCP sont exprimées et régulées de façon différentielles (Collin et al 2005, tableau 3) mais il reste difficile de conclure sur leur rôle physiologique dans le muscle. UCP2 est largement exprimée pendant la période fotale tandis que UCP3 est induite à la naissance. Contrairement à UCP2, UCP3 et avUCPs sont des effecteurs importants de l'effet de la T3 sur les dépenses énergétiques et pourraient jouer un rôle clé dans le contrôle du métabolisme basal. En revanche, seule avUCP semble impliquée dans les réponses à l'environnement thermique. L'implication dans le métabolisme lipidique est peu claire et pourrait davantage concerner avUCP et UCP2. Une revue plus détaillée sur le rôle des UCPs musculaires est jointe à ce dossier (Damon et Collin 2006).

\section{4 / Etude du rôle d'un dys- fonctionnement mitochon- drial dans la fonte muscu- laire}

\section{1 / Contexte et objectifs}

$\mathrm{Au}$ cours du vieillissement, une réduction de la masse des protéines musculaires est observée. Ce phénomène contribue à limiter la mobilité des personnes âgées et les rend plus fragiles en cas de stress nutritionnel, traumatique ou infectieux. Les mitochondries pourraient jouer un rôle crucial dans ce phénomène. En effet, ces organites sont au cour de la théorie radicalaire dans laquelle le vieillissement d'un organisme est expliqué par l'accumulation de dommages oxydatifs (Harman 1956). Les mitochondries constituent en effet une source importante de radicaux libres $\left(\mathrm{O}_{2}{ }^{-}, \mathrm{H}_{2} \mathrm{O}_{2}\right)$ qui peuvent diffuser dans la cellule s'ils ne sont pas détoxifiés (figure 7) et provoquer des altérations cellulaires et mitochondriales au niveau de l'ADN, des membranes, ou des protéines. L'apparition d'un déséquilibre entre la détoxification et la production mitochondriale de radicaux libres (PMRL) avec l'âge dans le muscle pourrait donc jouer un rôle dans le développement de la fonte musculaire, soit en induisant des dysfonctionnements mitochondriaux capables de limiter l'approvisionnement en énergie de la cellule, soit en perturbant la fonctionnalité cellulaire, en particulier via une stimulation de la protéolyse après oxydation des protéines musculaires.

Une augmentation de la PMRL avec l'âge peut notamment provenir d'une rupture de l'homéostasie calcique. En effet, au cours du vieillissement, la teneur en calcium cytosolique musculaire risque d'augmenter car l'activité des pompes captant le calcium au cours de la relaxation musculaire diminue (Viner et al 1999) ; de plus, l'insulinorésistance, fréquente au cours du vieillissement, s'accompagne également d'une augmentation du calcium cytosolique. Or, les mitochondries captent les excès physiologiques ou pathologiques de calcium et l'on sait que le calcium stimule la PMRL en induisant un réarrangement de la membrane 
Figure 7. Production et détoxification des radicaux libres par les mitochondries. Les mitochondries produisent l'anion superoxyde qui est détoxifié in situ par la superoxyde dismutase en $\mathrm{H}_{2} \mathrm{O}_{2}$ évitant ainsi la formation de peroxynitrite. $\mathrm{L}^{\prime} \mathrm{H}_{2} \mathrm{O}_{2}$ est transformé en eau par la glutathion peroxidase (GPX) ou diffuse à travers la membrane mitochondriale et peut être détoxifié au niveau du cytosol par la catalase.

Chaîne respiratoire mitochondriale, complexes I et III

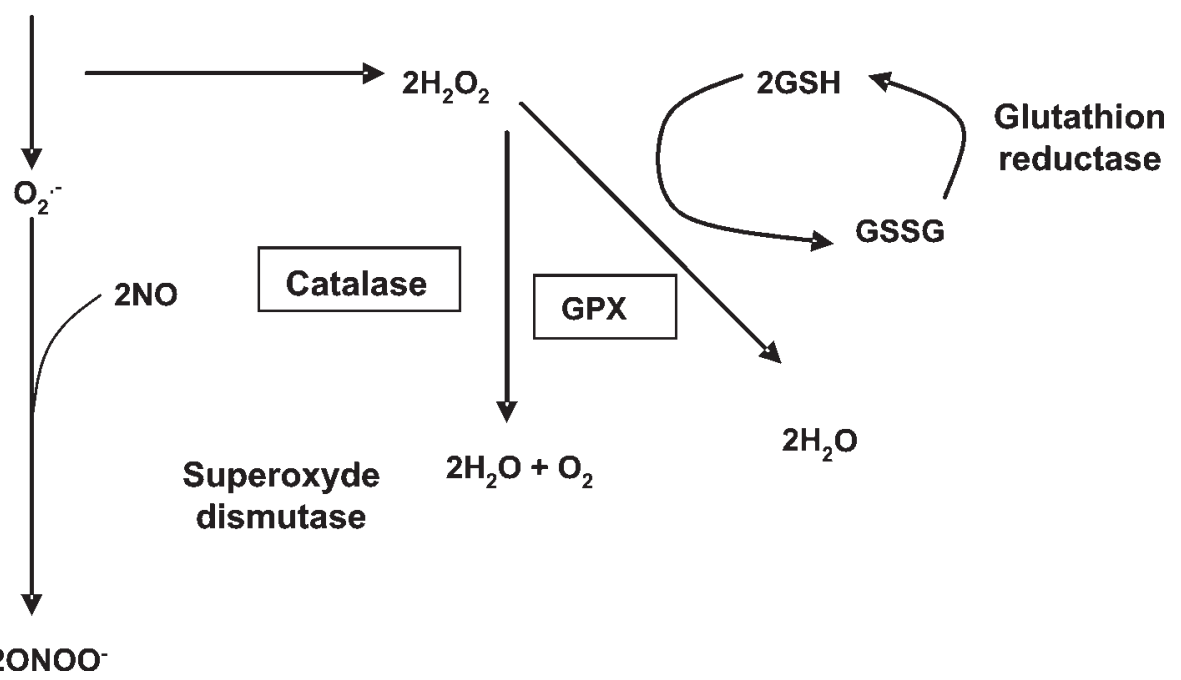

mitochondriale après interaction avec la cardiolipine (Grijalba et al 1999).

Nous avons donc mesuré l'évolution avec l'âge de la PMRL dans le muscle, étudié l'effet du calcium, et analysé l'impact de ces phénomènes : 1) sur les dommages affectant les mitochondries au cours du vieillissement ; 2) sur l'évolution avec l'âge du fonctionnement mitochondrial.

\section{2 / Evolution de la production mitochondriale de radicaux libres par les mitochondries au cours du vieillissement}

\section{a) Production basale}

Chez le rat, la production mitochondriale d' $\mathrm{H}_{2} \mathrm{O}_{2}$ évaluée en utilisant des substrats des complexes I ou II n'évolue pas entre 4,5 et 24 mois dans un muscle glycolytique ; cette production est par contre augmentée, avec des substrats du complexe I, dans un muscle oxydatif chez les rats âgés (Capel et al 2004). Parallèlement, des mesures effectuées sur un homogénat musculaire fortement appauvri en mitochondries suggèrent que la production extra mitochondriale $\mathrm{d}^{\prime} \mathrm{H}_{2} \mathrm{O}_{2}$ augmente également avec l'âge.

Chez l'homme, dans un muscle glycolytique (vastus lateralis), la production mitochondriale d' $\mathrm{H}_{2} \mathrm{O}_{2}$ (en présence de substrats des complexes I et II) augmente avec l'âge. En fait, les données bibliographiques démontrent l'existence d'un flux «inverse» d'élec- trons en présence de substrats à $\mathrm{FADH}_{2}$ (comme le succinate) entre les complexes II et I de la chaîne respiratoire, qui peut induire, comme le flux «normal», la formation d'anion superoxyde au niveau du complexe I (Liu et al 2002). Nous montrons ici que seule la production d' $\mathrm{H}_{2} \mathrm{O}_{2}$ liée au flux «inverse» d'électrons entre les complexes II et I augmente avec l'âge tandis que celle induite par le flux «normal» reste stable (Capel et al 2005b). De plus, la réduction de l'activité Glutathion Peroxydase (GPX) observée dans les muscles glycolytiques pourrait aggraver ce phénomène. Dans les muscles oxydatifs, la production mitochondriale $\mathrm{d}^{\prime} \mathrm{H}_{2} \mathrm{O}_{2}$ induite par le flux «normal» augmente avec l'âge mais il est possible qu'elle soit également accrue par d'autres voies. Nous montrons ainsi que la PMRL est accrue chez l'homme âgé dans tous les types musculaires.

\section{b) Effet du calcium}

L'impact d'un stress calcique sur la PMRL musculaire chez des rats adultes (6 mois) et âgés (21 mois) a été mesuré in vitro, sur mitochondries isolées, et in vivo, grâce à un modèle basé sur le traitement de rats avec un ionophore calcique, le A23187, qui induit un afflux de calcium dans le cytosol et les mitochondries (Capel et al 2005a).

In vitro, lorsque l'on incube les organites isolés à partir de muscles gastrocnémiens de ces rats adulte et âgés en présence de concentrations croissantes en calcium libre, ce calcium est immé- diatement capté par les mitochondries, mais les doses employées n'induisent pas de phénomène de transition de perméabilité (vérification à l'aide d'une sonde fluorescente). En présence de glutamate (état 2), la PMRL est fortement accrue $(+146 \%)$ lorsque la concentration en calcium libre du milieu passe de 2,7 à $19 \mu \mathrm{M}$. Le vieillissement musculaire amplifie notablement le phénomène $(+59 \%)$.

In vivo, le ionophore n'a aucun effet mesurable sur la concentration mitochondriale en calcium chez les rats adultes et l'augmente modérément chez les rats âgés. Ainsi, l'activité ICDH, marqueur de la concentration mitochondriale en $\mathrm{Ca}^{2+}$, mesurée $24 \mathrm{~h}$ après l'injection, a été augmentée de $40 \%$ dans les mitochondries de tous les animaux âgés traités. Cette augmentation n'est pas liée à un accroissement global du métabolisme mitochondrial puisque les activités CS et COX restent stables; elle reflète donc probablement une augmentation de la concentration mitochondriale en calcium. Dans ces conditions, le calcium augmente la PMRL musculaire. Nous observons également une corrélation inverse entre les teneurs mitochondriales en calcium à l'état basal et le poids des muscles suggérant un rôle du calcium dans la perte musculaire associée à l'âge. Enfin, le traitement au A23187 semble provoquer la dégénérescence d'une partie des mitochondries (activité $\mathrm{CS}$ réduit de $50 \%$ ) mais sur 24 ou $48 \mathrm{~h}$, la masse musculaire demeure inchangée (Capel et al 2005a).

Les rats âgés sont donc plus sensibles au stress calcique que les rats adultes. Cet accroissement du pool de calcium mitochondrial musculaire a induit une augmentation de la PMRL; de plus, in vitro, cette augmentation a été plus marquée pour les mitochondries des rats âgés. Ce phénomène pourrait donc initier un processus de transition de perméabilité membranaire conduisant à la mort cellulaire (Lemasters et al 1998). Une revue plus détaillée sur la production mitochondriale de radicaux libres dans le muscle et son évolution avec l'âge est jointe à ce dossier (Capel et al 2006).

\section{3 / Conséquences de l'augmen- tation avec l'âge de la produc- tion de radicaux libres sur les altérations mitochondriales dans le muscle}

Nous avons évalué les altérations du génome mitochondrial en mesurant l'évolution du nombre de copies de 
l'ADNmt par rapport à l'ADN nucléaire (Chabi et al 2005). Le nombre de copies de 4 fragments de gènes mitochondriaux (gènes de 2 sous unités du complexe I, de l'ARN ribosomique $16 \mathrm{~S}$ et d'une sous unité du complexe V) a été déterminé par PCR quantitative en temps réel (Chabi et al 2003) dans des biopsies musculaires de 22 sujets âgés de 14 à 87 ans, et rapporté à celui d'un gène nucléaire codant une sous unité du complexe $\mathrm{V}$ à copie unique. Ces rapports ont été très variables chez les 22 sujets étudiés, indépendamment de l'âge. Des études complémentaires ont montré que les 4 fragments d'ADNmt amplifiés étaient représentés avec un nombre de copies très voisin, indiquant qu'aucune zone de cet ADNmt n'était particulièrement sujette à délétion au cours du vieillissement. La quantification de la quantité totale d'ADNmt et des proportions d'ADNmt délété (ensemble des fragments $<16,6 \mathrm{~kb})$ et non délété $(16,6 \mathrm{~kb})$ chez chacun des 22 sujets a confirmé ce résultat. Contrairement à d'autres auteurs, nous n'observons pas d'accumulation de délétions de l'ADNmt au cours du vieillissement avant un âge très avancé (pas avant 80 ans) ; mais dans ce cas, elles peuvent atteindre plus de 60 à $80 \%$ de l'ADNmt cellulaire. La présence de multiples délétions a pu être vérifiée par un «screening PCR» chez les sujets de plus de 80 ans (analyse réalisée en collaboration avec les Hospices Civils de Lyon). Ces résultats ont été très récemment confirmé par plusieurs travaux (Mao et al 2006, Trifunovic 2006)

La mesure de la teneur en dérivés carbonylés des protéines mitochondriales de muscles de rats jeunes et âgés montre que le degré d'oxydation de ces protéines n'est pas modifié avec l'âge.

\section{4 / Conséquences de l'augmen- tation avec l'âge de la produc- tion de radicaux libres sur le fonctionnement mitochondrial musculaire des sujets âgés}

\section{a) Effet sur le fonctionnement mito- chondrial}

L'expression des gènes mitochondriaux présents dans le génome nucléaire (CS et sous-unité 4 de la COX) ou mitochondrial (sous-unité III de la $C O X$ ) ne diffère pas dans le muscle de sujets jeunes et âgés. Ainsi, la baisse d'activité CS observée au cours du vieillissement ne s'explique pas par une diminution de l'expression du gène. De plus, une étude exploratoire menée à l'aide de puces à ADN musculaires confirme l'absence de variations
Tableau 4. Evolution avec l'âge des activités enzymatiques mitochondriales dans le muscle chez le rat et chez l'homme.

\begin{tabular}{|c|c|c|c|}
\hline Activité & Espèce & Muscle & Effet de l'âge \\
\hline Complexe II & Homme & Quadriceps & $\leftrightarrow$ \\
& Homme & Vastus lateralis & $\leftrightarrow$ \\
& Rat & Gastrocnemius* & $\leftrightarrow$ \\
\hline Complexe III & Homme & Quadriceps & $\leftrightarrow$ \\
& Homme & Vastus lateralis & $\leftrightarrow$ \\
& Rat & Gastrocnemius* & $\leftrightarrow$ \\
\hline Complexe II + III & Rat & Tibialis anterior & $\leftrightarrow$ \\
\hline Complexe IV & Homme & Quadriceps & $\downarrow$ \\
& Homme & Vastus lateralis & $\leftrightarrow$ \\
& Homme & Vastus lateralis & $\leftrightarrow$ \\
& Rat & Gastrocnemius* & $\uparrow$ \\
& Rat & Tibialis anterior & $\leftrightarrow$ \\
\hline Citrate synthase & Homme & Quadriceps & $\downarrow$ \\
& Homme & Vastus lateralis & $\downarrow$ \\
& Homme & Vastus lateralis & $\leftrightarrow$ \\
& Rat & Tibialis anterior & $\downarrow$ \\
\hline CPT1 & Homme & Vastus lateralis & $\leftrightarrow$ \\
\hline HAD & Homme & Vastus lateralis & $\leftrightarrow$ \\
\hline
\end{tabular}

Complexe II = succinate-ubiquinone reductase ou succinate deshydrogénase ; complexe III = ubiquinol-cytochrome reductase $;$ complexe IV = cytochrome-c oxydase ; CPT1 = carnitine palmitoyltransferase $1 ; \mathrm{HAD}=$ B-Hydroxy-acyl-CoA Déshydrogénase.

* = mesuré sur mitochondries isolées. significatives d'expression des transcrits selon l'âge des sujets. De même, la mesure de différentes activités enzymatiques sur biopsies musculaires humaines (Chabi et al 2003) et muscles entiers de rat (tableau 4), montre que dans la plupart des cas l'activité enzymatique est maintenue au cours du vieillissement. Les résultats concernant l'activité du complexe IV sont plus discordants, mais montrent une tendance à un maintien de l'activité avec l'âge. Seule l'activité de la CS diminue au cours du vieillissement, ce qui pourrait également indiquer une diminution du nombre de mitochondries avec l'âge.

L'évolution de l'activité mitochondriale et de l'oxydation des acides gras va dans le même sens. La respiration mesurée à l'aide de plusieurs substrats dans différents muscles chez le rat (tableau 5) varie peu avec l'âge. Seule l'oxydation d'un substrat d'origine glu- cidique (le pyruvate) diminue avec le vieillissement (- $22 \%)$. L'oxydation de $[1-14 \mathrm{C}]$-palmitate par les mitochondries musculaires a été mesurée chez des hommes jeunes et âgés, sédentaires ou entraînés. Cette oxydation est inchangée avec l'âge, mais se révèle beaucoup plus élevée chez les sujets entraînés quel que soit l'âge. De plus, nous avons analysé les relations entre niveau d'activité physique et capacité d'oxydation des acides gras chez des sujets âgés (65,3 $\pm 3,4$ ans). La capacité d'oxydation des acides gras était significativement plus élevée chez les personnes âgées pratiquant plus de $25 \mathrm{mn}$ par jour d'activités sportives à une intensité supérieure à $60 \%$ de la consommation maximale d'oxygène (Rimbert et al 2004).

Le renouvellement des protéines mitochondriales a été déterminé en mesurant l'incorporation (taux de synthèse) de ${ }^{13} \mathrm{C}$-Leucine perfusée par
Tableau 5. Evolution avec l'âge de la respiration mitochondriale mesurée en présence de différents substrats sur mitochondries isolées de muscles de rats Wistar.

\begin{tabular}{|c|c|c|c|}
\hline Muscle & Substrat & Gamme d'âge & Effet de l'âge \\
\hline Gastrocnemius & Glutamate & 6 et 21 mois & $\leftrightarrow$ \\
\hline Gastrocnemius & Palmitoylcarnitine & 6 et 21 mois & $\leftrightarrow$ \\
\hline Gastrocnemius & Pyruvate & 6 et 21 mois & $-22 \%$ \\
\hline Tibialis anterior & Glutamate/ malate* & 5 et 24 mois & $\leftrightarrow$ \\
\hline Soleus & Glutamate/ malate* & 5 et 24 mois & $\leftrightarrow$ \\
\hline
\end{tabular}

\footnotetext{
${ }^{*}$ : Avec ou sans ADP.
} 
voie intraveineuse dans des biopsies musculaires de sujets jeunes et âgés (25 \pm 1 vs $72 \pm 2$ ans) en situation basale (à jeun) et lors d'une perfusion simultanée d'insuline et d'acides aminés. A jeun, une réduction des taux de synthèse des protéines mitochondriales est observée chez les sujets âgés. L'administration d'insuline et d'acides aminés s'accompagne d'une stimulation de la synthèse des protéines mitochondriales dans les deux groupes de sujets. Par contre, la réponse de la synthèse des protéines mitochondriales à ces deux facteurs est plus faible chez les sujets âgés, et ceci d'autant plus que les sujets âgés sont résistants à l'insuline. Ainsi, le renouvellement des protéines mitochondriales est affecté par l'âge, cependant, ces altérations semblent être étroitement liées à l'insulino-résistance apparaissant fréquemment avec l'âge (Guillet et al 2004).

\section{b) Effet sur la sénescence cellulaire}

D’une façon générale, le vieillissement des cellules en culture primaire se caractérise notamment par une diminution du nombre de divisions possibles en fonction de l'âge du donneur. Ainsi, pour des lignées de myoblastes issus de biopsies musculaires, le nombre de divisions possibles est de l'ordre d'une quarantaine chez les sujets jeunes et d'une dizaine seulement chez les sujets âgés. Il est possible de penser que les taux de mutation de l'ADNmt restent inchangés. Pour vérifier cette hypothèse, nous avons obtenu des cybrides par fusion entre des lignées cellulaires d'hépatocarcinome sans $\mathrm{ADNmt}\left(\mathrm{HepG} 2 \mathrm{rho}^{\circ}\right.$ ) et des lignées de myoblastes issus de sujets jeunes ou âgés. Ainsi, un même génome nucléaire (celui des cellules HepG $2 \mathrm{rho}^{\circ}$ ) était associé à des mitochondries de sujets jeunes ou âgés. Aucune différence significative du nombre maximum de divisions n'a été mise en évidence entre les deux types de lignées cybrides. Ceci indique que l'activité des mitochondries musculaires de personnes jeunes et âgées n'est pas à l'origine de la différence de survie cellulaire (Stépien et al non publié).

\section{c) Effet sur la sensibilité au calcium}

Les mitochondries peuvent tamponner l'excès cytosolique de calcium jusqu'à un seuil à partir duquel un phénomène de transition de perméabilité est induit, provoquant notamment une libération massive du calcium matriciel dans le cytosol. Avant cet événement, le fonctionnement mitochondrial est néanmoins perturbé (Martin et al accepté pour publication). Ainsi, quel que soit le substrat employé (glutamate ou pyruvate), l'augmentation du calcium dans la matrice mitochondriale se traduit par une diminution de l'état III respiratoire (- 36 à - 50\%) et du rapport ADP/O (- 25 à - $36 \%)$. La simultanéité des deux phénomènes suggère une forte diminution de la production d'ATP. Le vieillissement amplifie cet effet du calcium sur la respiration mitochondriale (diminution de $30 \%$ de l'état III et de $19 \%$ du rapport ADP/O avec le glutamate). Ainsi, lorsque la concentration en calcium libre s'élève anormalement dans le muscle, la production mitochondriale d'énergie diminue plus chez les animaux âgés. La quantité minimale de calcium nécessaire pour le déclenchement du phénomène de transition de perméabilité, indicateur de la capacité de rétention calcique des mitochondries, n'est pas altérée par la sénescence lors de l'oxydation du glutamate à l'état II. En revanche, en présence de pyruvate, elle est diminuée (35\%) chez les rats âgés. Or, ce phénomène est synonyme de gonflement mitochondrial, de rupture de la membrane externe et de libération de cytochrome c ; ainsi, en cas de stress calcique, les mitochondries musculaires des rats âgés présentent une plus grande susceptibilité à l'induction de la mort cellulaire (via une ouverture facilitée du pore de transition de perméabilité sous l'effet du calcium) (Martin et al soumis).

\section{5 / Conclusion}

Les mitochondries musculaires produisent plus de radicaux libres au cours du vieillissement, selon des mécanismes différents dans les muscles glycolytiques et oxydatifs. La baisse de l'activité GPX et l'augmentation de la production de radicaux libres extra mitochondriaux pourraient également contribuer à l'apparition d'un stress oxydant plus marqué au cours du vieillissement. De plus, la capacité de rétention calcique des mitochondries diminue, et lorsque le calcium mitochondrial augmente, la PMRL augmente plus chez les sujets âgés.

Malgré cette production accrue de radicaux libres, sur une population restreinte, nous n'observons pas d'accumulation d'ADNmt au cours du vieillissement ni de délétions de l'ADNmt avant un âge très avancé (après 80 ans). De plus, le fonctionnement mitochondrial reste relativement bien préservé. Ainsi, mis à part la citrate synthase, les activités enzymatiques se maintiennent avec l'âge, l'expression des gènes testés reste stable, la respiration mitochondriale est inchangée (sauf en présence de pyruvate), de même que l'oxydation des acides gras. Un modèle d'analyse du fonctionnement mitochondrial sur cybrides indique également un fonctionnement normal. Ainsi, même si certains de ces résultats doivent être précisés, les effets délétères du stress oxydant ne semblent s'exprimer que dans le grand âge (après 80 ans).

\section{Conclusions générales}

Nous apportons un certain nombre de résultats originaux qui constituent une contribution significative à la connaissance de l'importance physiologique des mitochondries, en particulier au niveau du développement, de l'activité et du vieillissement musculaire.

La relation entre activité mitochondriale et développement musculaire a été confirmée et certains de ses mécanismes élucidés. Ainsi, au-delà de la relation entre métabolisme oxydatif, densité mitochondriale et type contractile des fibres, nous montrons que les caractéristiques intrinsèques des organites diffèrent entre fonction des isoformes de myosine présentes. Les différences observées sont en parfait accord avec l'inhibition de l'activité respiratoire mitochondriale dans les fibres rapides au repos, tandis que les fibres IIA, bien que classées actuellement parmi les rapides, ont un fonctionnement mitochondrial très proche des fibres lentes. Certains de ces mécanismes sont mis en place très précocement, sur fibres primaires. De plus, bien que la différenciation contractile et métabolique des fibres musculaires s'effectue de manière parallèle, il semble que la densité mitochondriale diffère déjà dans les fibres primaires de muscles lent ou rapide, avant la mise en place de l'expression des myosines adultes. Or, les travaux réalisés in vitro sur myoblastes aviaires et murins montrent que l'activité mitochondriale, via le contrôle de l'expression de Calcineurine, constitue un déterminant majeur du type de myosine exprimée. Ces données sont confortées in vivo par l'obtention de souris surexpriment un récepteur mitochondrial de la T3 (p43) dans le muscle squelettique; en effet le pourcentage de fibres exprimant les myosines lentes et IIA dans le muscle Gastrocnemius (oxydoglycolytique) de 
ces animaux augmente fortement au détriment des fibres plus rapides. Ainsi, la nature des mitochondries et leur activité participent directement à la définition du type contractile des fibres musculaires. En dehors de leur intérêt fondamental, ces données sont importantes sur un plan agronomique dans la mesure où la biogenèse mitochondriale est notamment régulée par des facteurs d'élevage tels que l'alimentation ou l'exercice. Par ailleurs, les travaux in vitro ont permis d'établir que l'activité mitochondriale est également un régulateur important de la différenciation des myoblastes via le dialogue mitochondries-noyau dont la signalisation reste à mieux définir. En effet, parmi les gènes cibles de l'organite, trois sont à considérer comme des régulateurs majeurs de la différenciation musculaire : c-Myc (répresseur), Calcineurine et myogénine (stimulateurs).

Chez le bovin comme chez le porc, les mitochondries musculaires sont relativement immatures jusqu'aux deux tiers de la gestation; l'augmentation précise de leur activité survient parallèlement à l'augmentation des concentrations circulantes de T3 chez le fotus. Ces données suggérant une influence des hormones thyroïdiennes sur la biogenèse mitochondriale, sont en accord avec la démonstration in vivo (souris surexpriment la p43) et in vitro de l'importance de la voie d'action mitochondriale de la T3 pour la régulation de la mitochondriogenèse et de l'activité de l'organite.

Par contre, les résultats concernant les relations entre la quantité de lipides intramusculaires, un déterminant important de la qualité des viandes, et l'activité mitochondriale, n'ont pas permis de mettre en évidence une association très claire entre ces deux paramètres. Certes, l'exploitation de la variabilité de la teneur en LIM entre muscles, entre génotypes ou en fonction de l'âge montre que les muscles les plus riches en LIM sont généralement caractérisés par une activité oxydative et une activité CPT1 plus importante. Mais ces relations ne sont pas exclusives et des corrélations positives sont aussi trouvées avec le potentiel de synthèse et de transport des acides gras ; en d'autres termes, la teneur en LIM est davantage corrélée avec l'importance des flux de lipides dans le muscle qu'avec une voie métabolique particulière. En revanche, lorsqu'une sélection génétique est appliquée spécifiquement sur la teneur en LIM, avec la création d'une génération F2 de porcs
LW x Duroc présentant des teneurs élevées ou faibles en LIM, les différences de potentiel d'oxydation mitochondrial des acides gras ne sont pas significatives et aucune différence dans l'expression des isoformes musculaires et hépatiques de la CPT1 n'est observée. Dans ce cas, les meilleures corrélations sont observées entre la teneur en LIM, l'expression de la FABP-A et le nombre d'adipocytes intramusculaires. L'utilisation de manipulations alimentaires ou de conditions d'élevage modifiant l'activité physique des animaux fragilise encore davantage ce lien hypothétique entre activité oxydative mitochondriale et accumulation des LIM puisque les variations de ces deux paramètres ne sont que rarement corrélées chez le bovin, le mini-porc ou la truite. Ainsi, l'activité mitochondriale ne semble pas être un déterminant majeur de l'accumulation des LIM, qui parait dépendre davantage du turnover lipidique et de paramètres non mitochondriaux tels que la FABP-A, marqueur probable de la densité des adipocytes dans le muscle.

Les travaux concernant l'implication des UCPs dans le contrôle du métabolisme énergétique et lipidique musculaire ont porté essentiellement sur des espèces dépourvues de tissu adipeux brun. Ce choix s'est révélé judicieux puisque UCP2, UCP3 (chez le porc) et avUCP (chez le poulet) sont exprimées et régulées de façon différentielle. Alors que 1'UCP3 est induite dans le muscle à la naissance, l'expression d'UCP2 est détectée dans les myotubes primaires dès le stade foetal. L'expression préférentielle des UCP2 et UCP3 dans les muscles glycolytiques n'a pas été retrouvée chez le porc adulte alors qu'à contrario, chez le Poulet, avUCP aviaire est plus abondante dans les muscles mixtes. Contrairement à UCP2, UCP3 et avUCPs sont des effecteurs importants de l'effet thermogénique de la T3 et pourraient jouer un rôle clé dans le contrôle du métabolisme basal. Ce mécanisme a été élucidé puisque la stimulation de l'expression d'UCP3, spécifique au muscle glycolytique, s'accompagne d'une augmentation de la respiration mitochondriale et des fuites de protons. Par ailleurs, avUCP pourrait être un régulateur métabolique majeur chez le poulet puisque son expression est accrue lors d'une exposition au froid, diminuée lors d'une exposition à la chaleur, et qu'elle répond aux variations de l'intensité du métabolisme lipidique musculaire. Ces données démontrent donc que l'expres- sion des UCPs étudiées est régulée de manière différentielle mais il reste difficile de conclure sur leur rôle physiologique dans le muscle. La réponse de l'UCP aviaire à des modifications de l'environnement thermique, et sa forte régulation par la T3 l'impliquent probablement dans la régulation de la thermogenèse. Ceci est sans doute vrai, dans une moindre mesure, pour l'UCP3, moins étroitement régulée par la T3. Par contre, l'implication de ces UCPs dans le métabolisme lipidique reste à préciser, notamment pour l'UCP2 et l'UCP aviaire.

Les travaux concernant l'activité mitochondriale en relation avec le vieillissement ont produit un certain nombre de résultats divergents par rapport à la littérature. En effet, sur une population de 22 sujets, il n'a pas été possible de mettre en évidence une accumulation de délétions de l'ADN mitochondrial avant un âge très avancé. De même, l'expression de gènes mitochondriaux ou nucléaires codant des protéines à localisation mitochondriale n'est pas altérée avec l'âge, et l'activité de différentes enzymes est maintenue. Seule l'oxydation du pyruvate diminue avec l'âge. Les études in vitro réalisées sur cybrides provenant de la fusion de fibroblastes de personnes jeunes ou âgées avec des cellules HepG2 rho (dépourvues de mitochondries), montrent également que la sénescence de telles cellules, estimée par le nombre de divisions cellulaires après mise en culture, n'est pas modifiée par la présence de mitochondries musculaires de sujets «jeunes» ou «âgés».

Pourtant, chez l'Homme, la production d' $\mathrm{H}_{2} \mathrm{O}_{2}$ augmente avec l'âge dans les muscles oxydatifs et glycolytiques. L'origine de cette évolution est cependant différente selon le type de muscle (glycolytique : flux inverse d'électrons entre les complexes I et II ; oxydatif : flux normal d'électrons). Les conséquences de ces modifications sont par ailleurs renforcées par une augmentation de la production de $\mathrm{H}_{2} \mathrm{O}_{2}$ non mitochondriale et une diminution de l'activité de la GPX, enzyme de détoxification des radicaux libres. De plus, la production mitochondriale de radicaux libres est accrue en présence de quantités croissantes de calcium, et devient plus importante dans les mitochondries de rats âgés. Enfin, le vieillissement accroît la sensibilité de la respiration mitochondriale et du rapport $\mathrm{ADP} / \mathrm{O}$ au calcium et la sensibilité à l'apoptose induite par le calcium semble plus importante chez les rats âgés. 
Ainsi, si des altérations de l'ADN mitochondrial peuvent induire un vieillissement accéléré (Trifunovic et al 2004), il semble qu'une accumulation de délétions dans ce génome avec l'âge associée à une altération de l'activité de l'organite ne puisse être considérée comme une généralité. En revanche, l'augmentation de la production de radicaux libres au cours du vieillisse- ment et la modification de la sensibilité au calcium sont susceptibles de participer à l'induction «facilitée» d'une mort cellulaire.

\section{Références}

Alami-Durante H., Wrutniak Cabello C., Médale F., Rouel M., Rescan P.Y., Kaushik S., 2002. Nutritional regulation of trout skeletal muscle fibre size distribution and myosin heavy chain (MHC) expression by dietary proteins. In: Proceedings of the X Int. Fish Nut. Symp., 2-7 Juin 2002, Rhodes, Grèce, 199.

Bahi L, Garnier A, Fortin D, Serrurier B, Veksler V, Bigard AX, Ventura-Clapier R., 2005. Differential effects of thyroid hormones on energy metabolism of rat slow- and fast-twitch muscles. J. Cell Physiol., 203, 589-598.

Barnola I., Hocquette J.F., Cassar-Malek I., Jurie C., Gentès G., Cabaraux J.F., Cuvelier C., Istasse L., Dufrasne I., 2005. Adipocyte fatty acid-binding protein expression and mitochon-drial activity as indicators of intramuscular fat content in young bulls. In: Indicators of milk and beef quality, J.F. Hocquette, S. Gigli (Eds), EAAP Publication 112, Wageningen Academic Publishers, Wageningen, The Netherlands, 419-424.

Bouharaoua L., Barnola I., Jadhao S.B., Durand D., Bauchart D., Hocquette J.F., 2001. Influence de l'apport de 1'huile de tournesol ou de lin sur le métabolisme musculaire chez le bouvillon en croissance. Congrès commun AFERO, AFN et SNDLF Nutrition et Obésité 2001, 29-30 novembre 2001, Paris, France, Poster 86.

Brennan K.J., Hardeman E.C., 1993. Quantitative analysis of the human alpha-skeletal actin gene in transgenic mice. J. Biol. Chem., 268, 719-725.

Brun S., Carmona M.C., Mampel T., Vinas O., Giralt M., Iglesias R., Villarroya F., 1999. Uncoupling protein-3 gene expression in skeletal muscle during development is regulated by nutritional factors that alter circulating non-esterified fatty acids. FEBS Lett., 453, 205-209.

Bultot D., Dufrasne I., Istasse L., Jurie C., Hocquette J.F., 2002. Mise en évidence de facteurs métaboliques responsables du goût de la viande de bœuf : comparaison de races et de régimes. Renc. Rech. Rum., 9, 264.

Capel F., Buffière C., Patureau Mirand P., Mosoni L., 2004. Differential variation of mitochondrial $\mathrm{H}_{2} \mathrm{O}_{2}$ release during aging in oxidative and glycolytic muscles in rats. Mech. Ageing Dev., 125, 367-373.

Capel F., Demaison L., Maskouri F., Diot A., Buffière C., Patureau Mirand P., Mosoni L., 2005a. Calcium overload increases oxidative stress in old rat gastrocnemius muscle. J. Physiol. Pharmacol., 56, 369-380.

Capel F., Rimbert V., Lioger D., Diot A., Rousset P., Patureau Mirand P., Boirie Y., Morio B., Mosoni L., 2005b. Due to reverse electron transfer, mitochondrial $\mathrm{H}(2) \mathrm{O}(2)$ release increases with age in human vastus lateralis muscle although oxidative capacity is preserved. Mech. Ageing Dev., 126, 505-511.

Capel F., Demaison L., Morio B., Rimbert V., Patureau Mirand P., Mosoni L., 2006. Rôle des mitochondries dans le développement d'un stress oxydant dans le muscle squelettique au cours du vieillissement. INRA Prod. Anim., 19(4), 305318.

Casas F., Rochard P., Rodier A., Cassar-Malek I., Marchal-Victorion S., Wiesner R.J., Cabello G., Wrutniak C., 1999. A variant form of the nuclear T3 receptor c-Erb A $\alpha 1$ plays a direct role in regulation of mitochondrial RNA synthesis. Mol. Cell. Biol., 19, 7913-7924.

Casas F., Pessemesse L., Grandemange S., Seyer P., Gueguen N., Lepourry L., WrutniakCabello C., Cabello G., 2006. Involvement of the direct T3 mitochondrial pathway in mouse muscle development. 31 $3{ }^{\text {st }}$ Meeting of the European Thyroid Association, 2-6 sept. 2006, Naples, Italie, (sous presse)

Cassar-Malek I., Picard B., Kahl S., Hocquette J.F., 2006. Relationships between thyroid status, tissue oxidative metabolism, and muscle differentiation in bovine foetuses. Domest. Anim. Endocrinol., 19, (sous presse).

Cassy S., Collin A., Chartrin P., Baéza E., Jégo Y., 2005. Métabolisme oxydatif des acides gras et efficacité alimentaire chez le poulet. 6 èmes Journ. Rech. Avicole, 6, 325-329.

Chabi B., Mousson De Camaret B., Duborjal H., Issartel J.P., Stepien G., 2003. Quantification of mitochondrial DNA deletion, depletion and over-replication: application to the diagnosis. Clin. Chem., 49, 1309-1317.

Chabi B., Mousson De Camaret B. Chevrollier A., Boisgard S., Stepien G., 2005. Random mitochondrial DNA deletions and phenotypic consequence in aged human skeletal muscle. Biochem. Biophys. Res. Commun., $332,542-549$.

Chin E.R., Olson E.N., Richardson J.A., Yang Q., Humphries C., Shelton J.M., Wu H., Zhu W., Bassel-Duby R., Williams R.S., 1998. A calcineurin-dependent transcriptional pathway controls skeletal muscle fiber type. Genes Dev., 12, 2499-2509.

Collin A., Buyse J., Van As P., Darras V.M., Malheiros R.D., Moraes V.M.B., Reyns G.E., Taouis M., Decuypere E., 2003a. Cold-induced enhancement of avian uncoupling protein expression, heat production, and triiodothyronine concentrations in broiler chicks. Gen. Comp. Endocrinol., 130, 70-77.

Collin A., Taouis M., Buyse J., Ifuta N.B., Darras V.M., Van As P., Malheiros R.D., Moraes V.M., Decuypere E., 2003b. Thyroid status, but not insulin status, affects expression of avian uncoupling protein mRNA in chicken. Am. J. Physiol. Endocrinol. Metab., 284, E771E777.

Collin A., Cassy S., Buyse J., Decuypere E., Damon M., 2005. Potential involvement of mammalian and avian uncoupling proteins in the thermogenic effect of thyroid hormones. Domest. Anim. Endocrinol., 29, 78-87.
Crescenzi M., Crouch D.H., Tato F., 1994 Transformation by myc prevents fusion but not biochemical differentiation of $\mathrm{C}_{2} \mathrm{C}_{12}$ myoblasts: mechanisms of phenotypic correction in mixed culture with normal cells. J. Cell. Biol., 125, 1137-1145.

Damon M., Collin A., 2006. Quel est le rôle des protéines découplantes mitochondriales chez les mammifères et les oiseaux ? INRA Prod. Anim., 19(4), 287-304.

Damon M., Vincent A., Lombardi A., Herpin P., 2000. First evidence of uncoupling protein-2 (UCP-2) and -3 (UCP-3) gene expression in piglet skeletal muscle and adipose tissue. Gene, 246, 133-141.

Damon M., Gondret F., Louveau I., Lebret B., Lefaucheur L., Mourot J., Vincent A., Caritez J.C., Le Roy P., Herpin P. 2002. Comparaison de porcs présentant des teneurs extrêmes en lipides dans le muscle longissimus. 2- Capacités de stockage et d'utilisation des lipides intramusculaires.

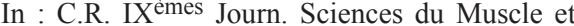
Technologies de la Viande, INRA, CTSCCV (Eds). Clermont-Ferrand, France, 167-168.

Damon M., Oswald I., Luron I., Hatey F., 2003. Apport des nouveaux outils de la postgénomique aux recherches en physiologie chez le porc. Journ. Rech. Porcine Fr., Paris, France, $35,339-354$.

Damon M., Louveau I., Lefaucheur L., Lebret B., Vincent A., Leroy P., Sanchez M.P., Herpin P., Gondret F., 2006. Number of intramuscular adipocytes and fatty acid binding protein 4 content are significant indicators of intramuscular fat level in crossbred Large White X Duroc pig. J. Anim. Sci., 84, 1083-1092.

De Lange P., Lanni A., Beneduce L., Moren M., Lombard A., Silvestri E., Goglia F., 2001. Uncoupling protein-3 is a molecular determinant for the regulation of resting metabolic rate by thyroid hormone. Endocrinol., 142, 3414-3420.

Delling U., Tureckova J., Lim H.W., De Windt L.J., Rotwein P., Molkentin J.D., 2000. A calcineurin-NFATc3-dependent pathway regulates skeletal muscle differentiation and slow myosin heavy-chain expression. Mol. Cell. Biol., 20, 6600-6611.

Dulloo A.G., Seydoux J., Jacquet J., 2004. Adaptive thermogenesis and uncoupling proteins: a reappraisal of their roles in fat metabolism and energy balance. Physiol. Behav., 83, 587-602.

Friday B.B., Horsley V., Pavlath G.K., 2000. Calcineurin activity is required for the initiation of skeletal muscle differentiation. J. Cell. Biol., 149, 657-666.

Gondret F., Hocquette J.F., Herpin P., 2004. Age-related relationships between muscle fat content and metabolic traits in growing rabbits. Reprod. Nutr. Dev., 44, 1-16.

Grijalba M.T., Vercesi A.E., Schreier S., 1999. $\mathrm{Ca} 2+$-induced increased lipid packing and 
domain formation in submitochondrial particles. A possible early step in the mechanism of $\mathrm{Ca} 2^{+-}$ stimulated generation of reactive oxygen species by the respiratory chain. Biochem., 38, 1327913287.

Grolli S., Accornero P., Ramoni R., Donofrio G., Whitelaw C.B., 1997. Expression of c-Myc is down-regulated as mouse mammary epithelial cells become confluent. Biochem. Biophys. Res. Commun., 239, 566-569.

Gueguen N., Lefaucheur L., Fillaut M., Vincent A., Herpin P., 2005a. Control of skeletal muscle mitochondria respiration by adenine nucleotides: differential effect of ADP and ATP according to muscle contractile type in pigs. Comp. Biochem. Physiol., 140B, 287-297.

Gueguen N., Lefaucheur L., Fillaut M., Herpin P., 2005b. Muscle fiber contractile type influences the regulation of mitochondrial function. Mol. Cell. Biochem., 276, 15-20.

Gueguen N., Lefaucheur L., Ecolan P., Fillaut M., Herpin P., 2005c. Ca ${ }^{2+}$-activated myosinATPases, creatine and adenylate kinases regulate mitochondrial function according to myofibre type. J. Physiol. (London), 564(3), 723-735.

Gueguen N., Lefaucheur L., Herpin P., 2006. Relations entre fonctionnement mitochondrial et type contractile des fibres musculaires. INRA Prod. Anim., 19(4), 265-278.

Guillerm-Regost C., Louveau I., Sébert S.P., Damon M., Champ M.M., Gondret F. 2006. Cellular and biochemical features of skeletal muscle in obese Yucatan minipigs. Obesity (sous presse).

Guillet C., Prod'homme M., Balage M., Gachon P., Giraudet C., Morin L., Grizard J., Boirie Y., 2004. Impaired anabolic response of muscle protein synthesis is associated with S6K1 dysregulation in elderly humans. FASEB J., 18(13), 1586-1587.

Gutières S., 2003. Régulation nutritionnelle de la carnitine palmitoyl transferase I chez la truite arc-en-ciel. Thèse Sciences des Aliments et Nutrition. Univ. Bordeaux 1, 141p.

Gutières S., Damon M., Panserat S., Kaushik S., Medale F., 2003. Cloning and tissue distribution of a carnitine palmitoyltransferase I gene in rainbow trout (Oncorhynchus mykiss). Comp. Biochem. Physiol., ser. B Biochem. Mol. Biol., $135,139-151$.

Harman D., 1956 Aging: a theory based on free radical and radiation chemistry. J.Gerontol., 11, 298-300.

Henriksson M., Luscher B., 1996. Proteins of the Myc network: essential regulators of cell growth and differentiation. Adv. Cancer Res., 68, 109-182.

Herpin P., Vincent A., Fillaut M., Bonito B., Hocquette J.F., 2003. Mitochondrial and peroxisomal $\beta$-oxidation capacities increase in the skeletal muscles of young pigs during early postnatal development but are not affected by cold stress. Reprod. Nutr. Dev., 43, 155-166.

Herpin P., Vincent A., Damon M., 2004. Effect of breed and body weight on thermoregulatory abilities of European (Piétrain (Landrace x Large White)) and Chinese (Meishan) piglets at birth. Livest. Prod. Sci., 88, 17-26.

Hesselink M.K., Mensink M., Schrauwen P., 2003. Human uncoupling protein-3 and obesity: an update. Obes. Res., 11, 1429-1443.

Hocquette J.F., Ortigues-Marty I., Pethick D.W., Herpin P., Fernandez X., 1998. Nutritional and hormonal regulation of energy metabolism in skeletal muscles of meat-producing animals. Livest. Prod. Sci., 56, 115-143.

Hocquette J.F., Jurie C., Sabboh H., Amarger V., Levéziel H., Bauchart D., Boulesteix P., Pethick D.W., 2002. Recherche d'indicateurs métaboliques et moléculaires du persillage de la viande bovine. 9 emes Journ. Sciences du Muscle et Technologies de la Viande. Clermont-Ferrand, France, 15-16 octobre 2002. Viandes et Produits Carnés, Numéro Hors Série, 145-146.

Hocquette J.F, Jurie C., Ueda Y, Boulesteix P., Bauchart D., Pethick D.W., 2003a. The relationship between muscle metabolic pathways and marbling of beef. In: Souffrant W.B., Metges C.C. (Eds), Progress in Research on Energy and Protein Metabolism. EAAP Publication 109, Wageningen Pers., The Netherlands, 513-516.

Hocquette J.F., Cabaraux J.F., Jurie C. Dufrasne I., Istasse L., 2003b. Metabolic properties of bovine muscles: regulation by genetic and nutritional factors. In: Abstracts of the $54^{\text {th }}$ Ann. Meet. Eur. Ass. Anim. Prod., Rome, Italie, August $\quad 31^{\text {st }}$-September $\quad 3^{\text {rd }}$ 2003, 9, Communication orale Ph6.1, abstract, 251.

Hocquette J.F., Barnola I., Jurie C., CassarMalek I., Picard B., Renand G., 2004. Teneur en lipides intramusculaires et fibres musculaires chez des taurillons Charolais. Renc. Rech. Rum., 11, 91-94.

Jurie C., Ortigues-Marty I., Picard B., Micol D., Hocquette J.F., 2006. R The separate effects of the nature of diet and grazing mobility on metabolic potential of muscles from Charolais steers. Livest. Sci., 104, 182-192.

Katsumata M., Matsumoto M., Kawakami S. Kaji Y., 2004. Effect of heat exposure on uncoupling protein-3 mRNA abundance in porcine skeletal muscle. J. Anim. Sci., 82, 3493-3499.

La Rocca S.A., Crouch D.H., Gillespie D.A., 1994. c-Myc inhibits myogenic differentiation and myoD expression by a mechanism which can be dissociated from cell transformation Oncogene, 9, 3499-3508.

Lebret B., Louveau I., Damon M., Gondret F., Lefaucheur L., Mourot J., Caritez J.C., Herpin P., Le Roy P., 2002. Comparaison de porcs présentant des teneurs extrêmes en lipides dans le muscle longissimus. 1- Performances de croissance et qualités des carcasses et des viandes. In: C.R. IXemes Journ. des Sciences du Muscle et Technologies de la viande, INRA, CTSCCV (Eds), 165-166.

Lemasters J.J., Nieminen A.L., Qian T., Trost L.C., Elmore S.P., Nishimura Y., Crowe R.A., Cascio W.E., Bradham C.A., Brenner D.A., Herman B., 1998. The mitochondrial permeability transition in cell death: a common mechanism in necrosis, apoptosis and autophagy. Bioch. Biophys. Acta, 1366, 177-196.

Liu Y., Fiskum G., Schubert D., 2002. Generation of reactive oxygen species by the mitochondrial electron transport chain. J. Neurochem., 80(5), 780-787.

Listrat A., Jurie C., Cassar-Malek I., Bouhraoua L., Picard B., Micol D., Hocquette J.F., 2001. Effect of grass feeding on muscle characteristics of finishing Charolais steers. Polish-French Symp. Animal and growth development: regulatory mechanisms. Paris, France, 25-26 September 2001. Reprod. Nutr. Dev., 42 , 508 .

Mao L., Zabel C., Wacker M.A., Nebrich G., Sagi D., Schrade P., Bachmann S., Kowald A., Klose J., 2006. Estimation of the mtDNA muta- tion rate in aging mice by proteome analysis and mathematical modeling. Exp. Gerontol., 41(1), $11-24$.

Martin C., Oudot A., Fontaine E., Vergely C., Keriel C., Rochette L., Leverve X., Demaison L., Abnormalities of mitochondrial functioning can explain the metabolic disorders encountered in sarcopenic gastrocnemius. Aging Cell (accepté).

Miner J.H., Wold B.J., 1991. c-Myc inhibition of MyoD and myogenin-initiated myogenic differentiation. Mol. Cell. Biol., 11, 2842-2851.

Orzechowski A., Hocquette J.F., Picard B., Cassar-Malek I., 2002. Elevated protein expression of respiratory chain enzymes is associated with metabolic differentiation of foetal skeletal muscle. XXII Congress of the Polish Physiological Society, Bydgoszcz, Poland, September 4-7 2002. J. Physiol. Pharmacol., 53 (Suppl. 1), 70

Raimbault S., Dridi S., Denjean F., Lachuer J., Couplan E., Bouillaud F., Bordas A., Duchamp C., Taouis M., Ricquier D., 2001. An uncoupling protein homologue putatively involved in facultative muscle thermogenesis in birds. Biochem. J., 353, 441-444.

Ricquier D., 2005. Respiration uncoupling and metabolism in the control of energy expenditure. Proc. Nutr. Soc., 64, 47-52.

Rimbert V., Boirie Y., Bedu M., Hocquette J.F., Ritz P., Morio B., 2004. Muscle fat oxidative capacity is not impaired by age but by physical inactivity: association with insulin sensitivity. FASEB J., 18(6), 737-739.

Rochard P., Rodier A., Casas F., Cassar-Malek I., Marchal-Victorion S., Daury L., Wrutniak C., Cabello G., 2000. Mitochondrial activity is involved in the regulation of myoblast differentiation through myogenin expression and activity of myogenic factors. J. Biol. Chem., 275, 2733 2744.

Rolfe D.F., Brand M.D., 1996. Contribution of mitochondrial proton leak to skeletal muscle respiration and to standard metabolic rate. Am. J Physiol., 271, C1380-C1389.

Rousset S., Alves-Guerra M.C., Mozo J., Miroux B., Cassard-Doulcier A.M., Bouillaud F., Ricquier D., 2004. The biology of mitochondrial uncoupling proteins. Diabetes, 53, S130-S135.

Ryan K.M., Birnie G.D., 1997. Cell-cycle progression is not essential for c-Myc to block differentiation. Oncogene, 14, 2835-2843.

Schmidt I., Herpin P., 1997. Postnatal changes in mitochondrial protein mass and respiration in skeletal muscle from the newborn pig. Comp. Biochem. Physiol. B Biochem. Mol. Biol., 118, 639-647.

Schrauwen P., Hoeks J., Schaart G., Kornips E., Binas B., Van De Vusse G.J., Van Bilsen M., Luiken J.J., Coort S.L., Glatz J.F., Saris W.H. Hesselink M.K., 2003. Uncoupling protein 3 as a mitochondrial fatty acid anion exporter. FASEB J., 17, 2272-2284.

Semsarian C., Wu M.J., Ju Y.K., Marciniec T. Yeoh T., Allen D.G., Harvey R.P., Graham R.M., 1999. Skeletal muscle hypertrophy is mediated by a $\mathrm{Ca} 2+-d e p e n d e n t$ calcineurin signalling pathway. Nature, 400, 576-81.

Seyer P., 2005. Implication directe de l'activité mitochondriale dans la régulation de la différenciation des myoblastes. Thèse d'Université, ENSA Montpellier, France, 151p.

Seyer P., Grandemange S., Busson M., Carazo A., Gamaleri F., Pessemesse L., Casas F., 
Cabello G., Wrutniak-Cabello C., 2006 a. Mitochondrial activity regulates myoblast differentiation by control of c-Myc expression. J. Cell Physiol., 207, 75-86.

Seyer P., Grandemange S., Pessemesse L., Casas F., Cabello G., Wrutniak-Cabello C., 2006b. L'activité mitochondriale est un régulateur majeur de la différenciation des myoblastes et de l'expression des isoformes de myosine. INRA Prod. Anim., 19(4), 279-286.

Siebenlist U., Bressler P., Kelly K., 1988. Two distinct mechanisms of transcriptional control operate on c-Myc during differentiation of HL60 cells. Mol. Cell. Biol., 8, 867-874.

Sudre K., Leroux C., Piétu G., Cassar-Malek I., Petit E., Listrat A., Auffray C., Picard B., Martin P., Hocquette J.F., 2003. Transcriptome analysis of two bovine muscles during ontogenesis. J. Biochem., 133, 745-756.

Sudre K., Cassar-Malek I., Listrat A., Ueda Y., Leroux C., Jurie C., Auffray C., Renand G.,
Martin P., Hocquette J.F., 2005. Biochemical and Transcriptomic analyses of two bovine skeletal muscles in Charolais bulls divergently selected for muscle growth. Meat Sci., 70, 267-277.

Taouis M., De Basilio V., Mignon-Grasteau S., Crochet S., Bouchot C., Bigot K., Collin A., Picard M., 2002. Early-age thermal conditioning reduces uncoupling protein messenger RNA expression in pectoral muscle of broiler chicks at seven days of age. Poultry Sci., 81, 1640-1643.

Touraille C., 1994. Incidence des caractéristiques musculaires sur les qualités organoleptiques des viandes. Renc. Rech. Rum., 1, 169176.

Trifunovic A., Wredenberg A., Falkenberg M., Spelbrink J.N., Rovio A.T., Bruder C.E., Bohlooly-Y M., Gidlof S., Oldfors A., Wibon R. Tornell J., Jacobs H.T., Larsson N.G., 2004. Premature ageing in mice expressing defective mitochondrial DNA polymerase. Nature, 429, 417-423.
Trifunovic A., 2006. Mitochondrial DNA and ageing. Biochim. Biophys. Acta., 1757(5-6), 611-617.

Viner R.I., Ferrington D.A., Williams T.D., Bigelow D.J., Schoneich C., 1999. Protein modification during biological aging: selective tyrosine nitration of the SERCA $2 \mathrm{a}$ isoform of the sarcoplasmic reticulum Ca2+-ATPase in skeletal muscle. Biochem J., 340, 657-669.

Wrutniak C., Cassar-Malek I., Marchal S., Rascle A., Heusser S., Keller J.M., Flechon J., Dauça M., Samarut J., Ghysdael J., Cabello G. 1995. A $43 \mathrm{kDa}$ protein related to c-erb A $\alpha 1$ is located in the mitochondrial matrix. of rat liver. J. Biol. Chem., 270, 16347-16354.

Wrutniak-Cabello C., Casas F., Cabello G., 2001. Thyroid hormone action in mitochondria. J. Mol. Endocr., 26, 67-77.

\section{Résumé}

Cette synthèse concerne les recherches récemment effectuées à l'INRA sur le rôle des mitochondries dans la régulation du développement, de la croissance et des propriétés du muscle des animaux d'élevage et dans le déterminisme de la fonte musculaire au cours du vieillissement chez l'homme.

La relation entre activité mitochondriale et développement musculaire a été confirmée. Au-delà de la relation entre métabolisme oxydatif, densité mitochondriale et type contractile des fibres, nous montrons que les caractéristiques intrinsèques des organites diffèrent en fonction des isoformes de myosine présentes. Les mitochondries participent à la définition du type contractile et à la différenciation des myoblastes, via le dialogue mitochondries-noyau auquel participent trois gènes cibles majeurs de l'organite : c-Myc (répresseur), Calcineurine et myogénine (stimulateurs). L'importance de la voie d'action mitochondriale de la T3 pour la régulation de la mitochondriogenèse et de l'activité de l'organite est confirmée à la fois in vitro et in vivo.

Aucune relation claire n'a été mise en évidence entre la quantité de lipides intramusculaires (LIM), un déterminant important de la qualité des viandes, et l'activité mitochondriale. La teneur en LIM semble davantage corrélée avec la différenciation des adipocytes intramusculaires et l'importance des flux de lipides dans le muscle qu'avec une voie métabolique particulière.

Les protéines découplantes, UCP2, UCP3 (chez le porc) et avUCP (chez le poulet) sont régulées différemment mais il reste difficile de conclure sur leur rôle physiologique. UCP3 et avUCPs sont des effecteurs importants de l'effet thermogénique de la T3 et pourraient jouer un rôle dans le contrôle du métabolisme basal, tandis qu'avUCP semble être un régulateur métabolique majeur chez le poulet.

Les travaux concernant l'activité mitochondriale en relation avec le vieillissement ont produit un certain nombre de résultats divergents par rapport à la littérature : absence d'accumulation de délétions de l'ADN mitochondrial et d'altération de l'expression de gènes mitochondriaux ou nucléaires avant un âge très avancé. Pourtant, la production mitochondriale d' $\mathrm{H}_{2} \mathrm{O}_{2}$ augmente avec l'âge et le vieillissement accrô̂t la sensibilité de la respiration mitochondriale au calcium, deux phénomènes susceptibles de participer à l'induction «facilitée» d'une mort cellulaire.

En conclusion, que ce soit chez l'animal ou l'homme, les mitochondries musculaires participent à de nombreuses fonctions physiologiques en liaison avec leurs différentes activités biologiques.

\section{Abstract}

\section{Implication of mitochondria in muscular biology: a key role during early development, growth and muscular atrophy.}

Mitochondria are implicated in the regulation of biological process controlling development, growth and muscle properties in farm animals, as well as sarcopenia during aging in humans. Recent results obtained at INRA on these aspects are reviewed in this paper.

First, the relationship between oxidative metabolism, mitochondria density and muscle contractile type is confirmed, and the specificity of mitochondria properties according to myosin isotypes is demonstrated. Contribution of mitochondria to the acquisition of muscle contractile types and to myoblast differentiation, through the mitochondria-nuclear cross-talk, is described, and the key roles of c-Myc, Calcineurine and myogenin in this process is clearly established. The involvement of the direct T3 mitochondrial pathway in the regulation of mitochondrial biogenesis and activity is confirmed both in vitro and in vivo. 
No clear relation is found between mitochondrial activity and the amount of intramuscular fat, a key component of meat quality. In fact, muscle lipid content appears to be more related to intra-muscular adipocyte differentiation and lipid turnover rate than to any metabolic pathway.

We also show in pigs and chickens that uncoupling proteins, UCP2, UCP3 and avUCP are differentially regulated in the muscle, but it is still difficult to conclude on their physiological roles. UCP3 and avUCP are clearly implicated in the thermogenic effect of T3 and probably play a role in the control of basal metabolism, whereas avUCP can be seen as a key metabolic sensor in the chicken because its expression is modified by cold or warm exposure and correlated to the intensity of lipid metabolism.

Finally, mitochondrial $\mathrm{H}_{2} \mathrm{O}_{2}$ production increases during healthy aging but has no short-term effect on muscle aging (sarcopenia). In fact, accumulation of mitochondrial DNA deletions and alteration of the expression of mitochondrial or nuclear genes are only observed in very old patients (older than 80). However, sensitivity of mitochondrial respiration to calcium clearly increases with aging, a process that could contribute to the reduction of aged muscle resistance to stress and to the development of apoptosis.

HERPIN P., DAMON M., HOCQUETTE J.-F., MÉDALE F., MOSONI L., STÉPIEN G., WRUTNIAK-CABELLO C., CABELLO G., 2006. Implication des mitochondries dans la biologie musculaire : un rôle clé au cours du développement, de la croissance et de la fonte musculaire. INRA Prod. Anim., 19, 245-264. 
